\title{
Optimisation of a thermal desorption-gas chromatography-mass spectrometry method for the analysis of monoterpenes, sesquiterpenes and diterpenes
}

Aku Helin et al.

Correspondence to: Aku Helin (aku.helin@fmi.fi)

The copyright of individual parts of the supplement might differ from the CC BY 4.0 License. 


\section{Contents}

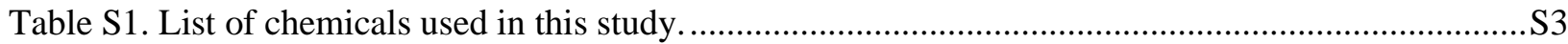

Table S2. Both TD-GC-MS's instrumental parameters and analysis conditions presented ......................S4

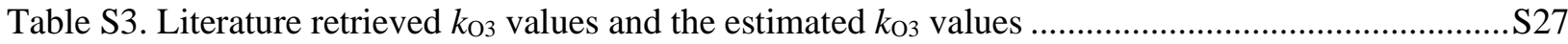

Table S4. Tentative identification of diterpenoids and alike compounds in dynamic headspace samples of

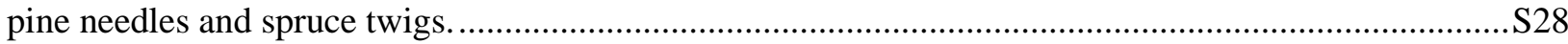

Table S5. Results from the spruce branch enclosure experiments....................................................... 33

Figure S1. Illustration of the experimental setups used in the inlet line sampling (a-b) and cuvette (c)

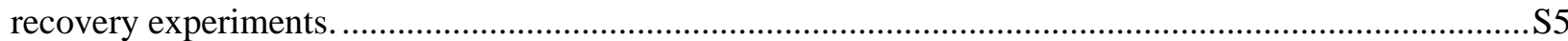

Figure S2. Schematic illustration of the experimental setup used for the comparison of online and offline mode TD-GC-MS sampling and analysis.

Figure S3. Illustration of the experimental setup used for studying of the compound stability in sorbent tube upon ozone exposure.

Figure S4. Illustration of the experimental setup used for the purge-and-trap type of headspace extraction of the pine needles and spruce twigs.

Figure S5. Cuvette inside temperature during the heating cycle on the different sampling dates of branch

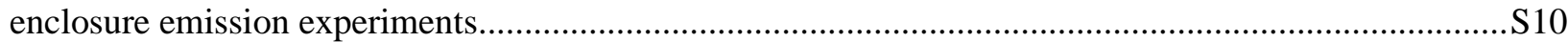

Figure S6. Schematic illustration of the setup used for branch enclosure emission measurements. ........S11

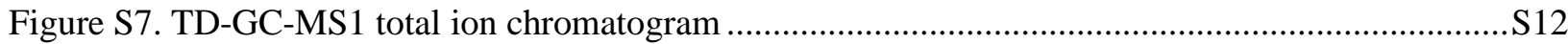

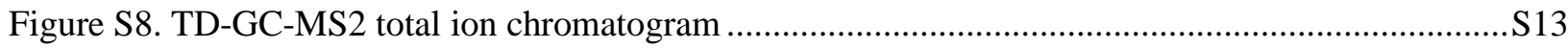

Figure S9. Stability of the analytes in sorbent tube during storage ....................................................... S14

Figure S10. Schematic diagram of the conventional online sampling mode in the TD ..........................S15

Figure S11. Recoveries obtained with three different empty stainless-steel tubes tested in online sampling.

Figure S12. Recovery results obtained when empty glass tube was used in online sampling. S18

Figure S13. The effect of relative humidity on analyte recoveries when using a) stainless-steel empty tube or b) glass tube.

Figure S14. The results obtained after the TD unit line changes from stainless-steel lines to Teflon lines.

Figure S15. Comparison of the recovery levels obtained when using either stainless-steel, glass tube or glass inner surface coated stainless-steel tube in online sampling.

Figure S16. Effect of relative humidity on recoveries when the glass coated empty stainless-steel tube was used in online sampling.

Figure S17. Results from the ozone exposure experiments.

Figure S18. Terpenoid emission rates from pine needles as a function of oven temperature in the dynamic headspace extraction experiments.

Figure S19. Terpenoid emission rates from spruce twigs as a function of oven temperature in the dynamic headspace extraction experiments..... 
Figure S20. Selected ion recording chromatograms from the TD-GC-MS2 analysis of spruce branch enclosure experiment sample... 
Table S1. List of chemicals used in this study.

\begin{tabular}{|c|c|c|c|}
\hline Compound & CAS Number & Purity & Supplier \\
\hline$\alpha$-pinene & $7785-70-8$ & analytical standard & Sigma-Aldrich (St.Louis, MO, USA) \\
\hline camphene & $79-92-5$ & $95 \%$ & Sigma-Aldrich (Steinheim, Germany) \\
\hline$\beta$-pinene & $19902-08-0$ & analytical standard & Sigma-Aldrich (St.Louis, MO, USA) \\
\hline 3-carene & 498-15-7 & analytical standard & Sigma-Aldrich (St.Louis, MO, USA) \\
\hline$p$-cymene & $99-87-6$ & analytical standard & Sigma-Aldrich (St.Louis, MO, USA) \\
\hline limonene & $5989-54-8$ & $\geq 99.0 \%$ & Sigma-Aldrich (Buchs, Switzerland) \\
\hline 1,8-cineol & $470-82-6$ & $99 \%$ & Sigma-Aldrich (Gillingham, Dorset, UK) \\
\hline terpinolene & $586-62-9$ & $\sim 95 \%$ & Fluka Chemie AG (Buchs, Switzerland) \\
\hline linalool & $78-70-6$ & $97 \%$ & Sigma-Aldrich (St.Louis, MO, USA) \\
\hline $\begin{array}{l}\text { 4-acetyl-1- } \\
\text { methylcyclohexene } \\
\text { (4-AMCH) }\end{array}$ & $6090-09-1$ & $98 \%$ & Sigma-Aldrich (Milwaukee, WI, USA) \\
\hline nopinone & $38651-65-9$ & $98 \%$ & Sigma-Aldrich (St.Louis, MO, USA) \\
\hline bornylacetate & $5655-61-8$ & $97 \%$ & Sigma-Aldrich (Milwaukee, WI, USA) \\
\hline longicyclene & $1137-12-8$ & $\geq 95 \%$ & Sigma-Aldrich (St.Louis, MO, USA) \\
\hline isolongifolene & $1135-66-6$ & $\geq 98 \%$ & Sigma-Aldrich (St.Louis, MO, USA) \\
\hline$\beta$-caryophyllene & $87-44-5$ & $\geq 98.5 \%$ & Sigma-Aldrich (St.Louis, MO, USA) \\
\hline$\beta$-farnesene & $18794-84-8$ & $\geq 90 \%$ & Sigma-Aldrich (St.Louis, MO, USA) \\
\hline$\alpha$-humulene & $6753-98-6$ & $\geq 96.0 \%$ & Sigma-Aldrich (St.Louis, MO, USA) \\
\hline caryophyllene oxide & $1139-30-6$ & $\geq 99.0 \%$ & Sigma-Aldrich (St.Louis, MO, USA) \\
\hline cembrene & $1898-13-1$ & $95 \%$ & Combi-Blocks (San Diego, CA, USA) \\
\hline ent-kaurene & $562-28-7$ & $90 \%$ & BOC Sciences (info@bocsci.com) \\
\hline $\begin{array}{l}\text { 3-methylene-5- } \alpha \text { - } \\
\text { androstane (3-MA) }\end{array}$ & Not assigned & crude & Sigma-Aldrich (St.Louis, MO, USA) \\
\hline methanol & $67-56-1$ & $\geq 99.9 \%$ & VWR Chemicals (Gliwice, Poland) \\
\hline $\begin{array}{l}\text { ultrapure water } \\
\mathrm{C}_{8}-\mathrm{C}_{40} \text { alkanes }\end{array}$ & - & - & Milli-Q Gradient (Molsheim, France) \\
\hline $\begin{array}{l}\text { calibration standard } \\
\text { (in dichloromethane) }\end{array}$ & - & - & Sigma-Aldrich (St.Louis, MO, USA) \\
\hline
\end{tabular}


Table S2. Both TD-GC-MS's instrumental parameters and analysis conditions presented.

\begin{tabular}{|c|c|c|}
\hline Equipment/Parameter & TD-GC-MS 1 & TD-GC-MS 2 \\
\hline & TurboMatrix 350 & TurboMatrix 650 \\
\hline Thermal desorption unit & $\begin{array}{c}\text { (PerkinElmer Inc., Waltham, } \\
\text { MA, USA) }\end{array}$ & $\begin{array}{c}\text { (PerkinElmer Inc., Waltham, } \\
\text { MA, USA) }\end{array}$ \\
\hline Cold trap & $\begin{array}{c}\text { Tenax TA/Carboback B } \\
\text { (PerkinElmer Inc., Waltham, MA, } \\
\text { USA) }\end{array}$ & $\begin{array}{c}\text { Tenax TA } \\
\text { (PerkinElmer Inc., Waltham, MA, } \\
\text { USA) }\end{array}$ \\
\hline $\begin{array}{c}\text { Pre-purge time } \\
\text { [sorbent tube purging] }\end{array}$ & $1 \mathrm{~min}$ (He flow rate $50 \mathrm{~mL} / \mathrm{min}$ ) & $5 \mathrm{~min}$ (He flow rate $50 \mathrm{~mL} / \mathrm{min})$ \\
\hline $\begin{array}{l}\text { Primary desorption } \\
\text { [sorbent tube desorption] }\end{array}$ & $\begin{array}{c}5 \mathrm{~min} \text { at } 300{ }^{\circ} \mathrm{C} \\
\text { (desorption flow rate } 50 \mathrm{~mL} / \mathrm{min} \text {, } \\
\text { no split flow applied) }\end{array}$ & $\begin{array}{c}5 \mathrm{~min} \text { at } 300{ }^{\circ} \mathrm{C} \\
\text { (desorption flow rate } 50 \mathrm{~mL} / \mathrm{min} \text {, } \\
\text { no split flow applied) }\end{array}$ \\
\hline $\begin{array}{l}\text { Secondary desorption } \\
\text { [cold trap desorption] }\end{array}$ & $\begin{array}{l}\text { Initial temperature } 20^{\circ} \mathrm{C} \text {, then } \\
\text { heated to } 300{ }^{\circ} \mathrm{C} \text { for } 1 \mathrm{~min} \text {. } \\
\text { (desorption flow rate } 10 \mathrm{~mL} / \mathrm{min} \text {, } \\
\text { outlet split) }\end{array}$ & $\begin{array}{c}\text { Initial temperature } 20^{\circ} \mathrm{C} \text {, then } \\
\text { heated to } 300^{\circ} \mathrm{C} \text { for } 5 \mathrm{~min} \\
\text { (desorption flow rate } 30 \mathrm{~mL} / \mathrm{min} \text {, } \\
\text { outlet split) }\end{array}$ \\
\hline Heated valve temperature & $220^{\circ} \mathrm{C}$ & $220^{\circ} \mathrm{C}$ \\
\hline $\begin{array}{l}\text { Heated transfer line } \\
\text { [between TD and GC] }\end{array}$ & $\begin{array}{l}\text { deactivated fused silica (ca. } 1 \mathrm{~m} \mathrm{x} \\
0.25 \text { (i.d.)), Agilent Technologies, } \\
\text { Palo Alto, USA) heated to } 200^{\circ} \mathrm{C}\end{array}$ & $\begin{array}{l}\text { deactivated fused silica (ca. } 1 \mathrm{~m} \mathrm{x} \\
0.25 \text { (i.d.)), Agilent Technologies, } \\
\text { Palo Alto, USA) heated to } 200^{\circ} \mathrm{C}\end{array}$ \\
\hline Gas chromatograph & $\begin{array}{c}\text { Clarus } 680 \\
\text { (PerkinElmer Inc., Waltham, } \\
\text { MA, USA) }\end{array}$ & $\begin{array}{c}\text { Clarus } 600 \\
\text { (PerkinElmer Inc., Waltham, } \\
\text { MA, USA) }\end{array}$ \\
\hline Column & $\begin{array}{c}\text { Elite-5 MS (60 m x } 0.25 \mathrm{~mm} \text { (i.d.), } \\
0.25 \mathrm{um} \text { film thickness, } \\
\text { PerkinElmer Inc., Waltham, MA, } \\
\text { USA) }\end{array}$ & $\begin{array}{l}\text { DB-5MS (50 m x } 0.25 \mathrm{~mm} \text { (i.d.), } \\
0.25 \text { um film thickness, Agilent } \\
\text { Technologies, Palo Alto, USA) }\end{array}$ \\
\hline Temperature program & $\begin{array}{c}60{ }^{\circ} \mathrm{C}(2 \mathrm{~min})-->300{ }^{\circ} \mathrm{C} \text { at } 8{ }^{\circ} \mathrm{C} \\
/ \mathrm{min}-->300{ }^{\circ} \mathrm{C}(15 \mathrm{~min})\end{array}$ & $\begin{array}{c}60{ }^{\circ} \mathrm{C}(2 \mathrm{~min})-->300^{\circ} \mathrm{C} \text { at } 8{ }^{\circ} \mathrm{C} \\
/ \text { min --> } 300{ }^{\circ} \mathrm{C}(3 \mathrm{~min})\end{array}$ \\
\hline Flow rate & $\begin{array}{c}1 \mathrm{~mL} / \mathrm{min} \text { (constant flow mode) } \\
\text { Helium }\end{array}$ & $\begin{array}{c}1 \mathrm{~mL} / \mathrm{min} \text { (constant flow mode) } \\
\text { Helium }\end{array}$ \\
\hline Carrier gas & $\begin{array}{c}(\geq 99.9996 \%, \text { AGA, Espoo, } \\
\text { Finland) }\end{array}$ & $\begin{array}{c}(\geq 99.9996 \% \text {, AGA, Espoo, } \\
\text { Finland) }\end{array}$ \\
\hline Interface temperature & $220^{\circ} \mathrm{C}$ & $220^{\circ} \mathrm{C}$ \\
\hline Mass spectrometer & $\begin{array}{c}\text { Clarus SQ } 8 \text { T } \\
\text { (PerkinElmer Inc., Waltham, } \\
\text { MA, USA) }\end{array}$ & $\begin{array}{c}\text { Clarus } 600 \mathrm{~T} \\
\text { (PerkinElmer Inc., Waltham, } \\
\text { MA, USA) }\end{array}$ \\
\hline Mass analyzer & quadrupole & quadrupole \\
\hline Ion source temperature & $150^{\circ} \mathrm{C}$ & $150^{\circ} \mathrm{C}$ \\
\hline Electron ionization & $70 \mathrm{eV}$ & $70 \mathrm{eV}$ \\
\hline Scan range & $\mathrm{m} / \mathrm{z} 50-350$ & $\mathrm{~m} / \mathrm{z} 50-350$ \\
\hline
\end{tabular}




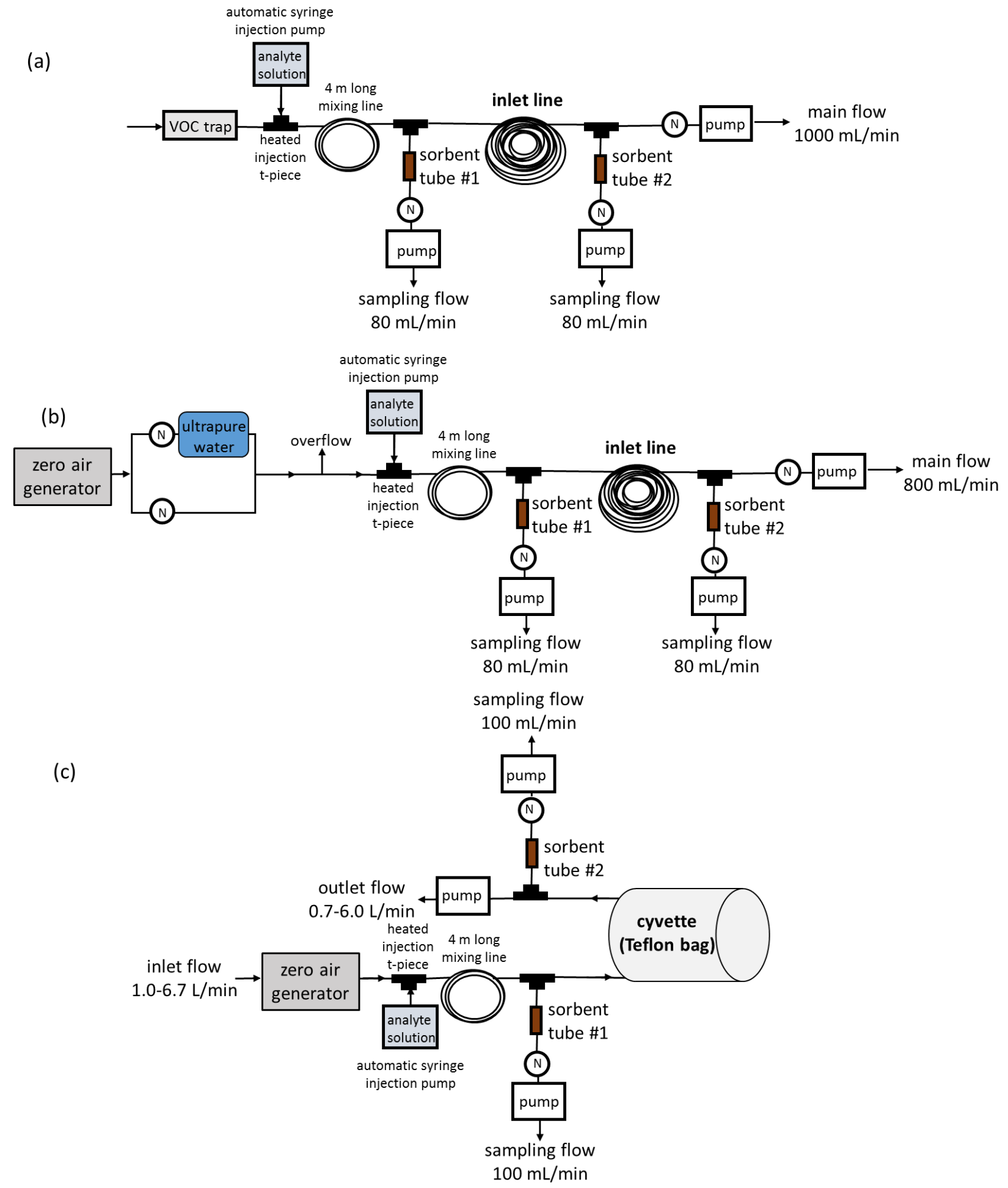

Figure S1. Illustration of the experimental setups used in the inlet line sampling (a-b) and cuvette (c) recovery experiments. (a) Experiments performed at room temperature and relative humidity (RH). (b) Experiments performed at room temperature at different RH levels. In both (a) and (b), the analyte solution was injected at a flow rate of $15 \mu \mathrm{L} / \mathrm{h}$ and the sorbent sampling time was $20 \mathrm{~min}$. In (c), the injection flow rate was between $20-105 \mu \mathrm{L} / \mathrm{h}$ and the sampling time was $30 \mathrm{~min}$. In all experiments, the injection t-piece was heated to $60 \pm 5^{\circ} \mathrm{C}$. 


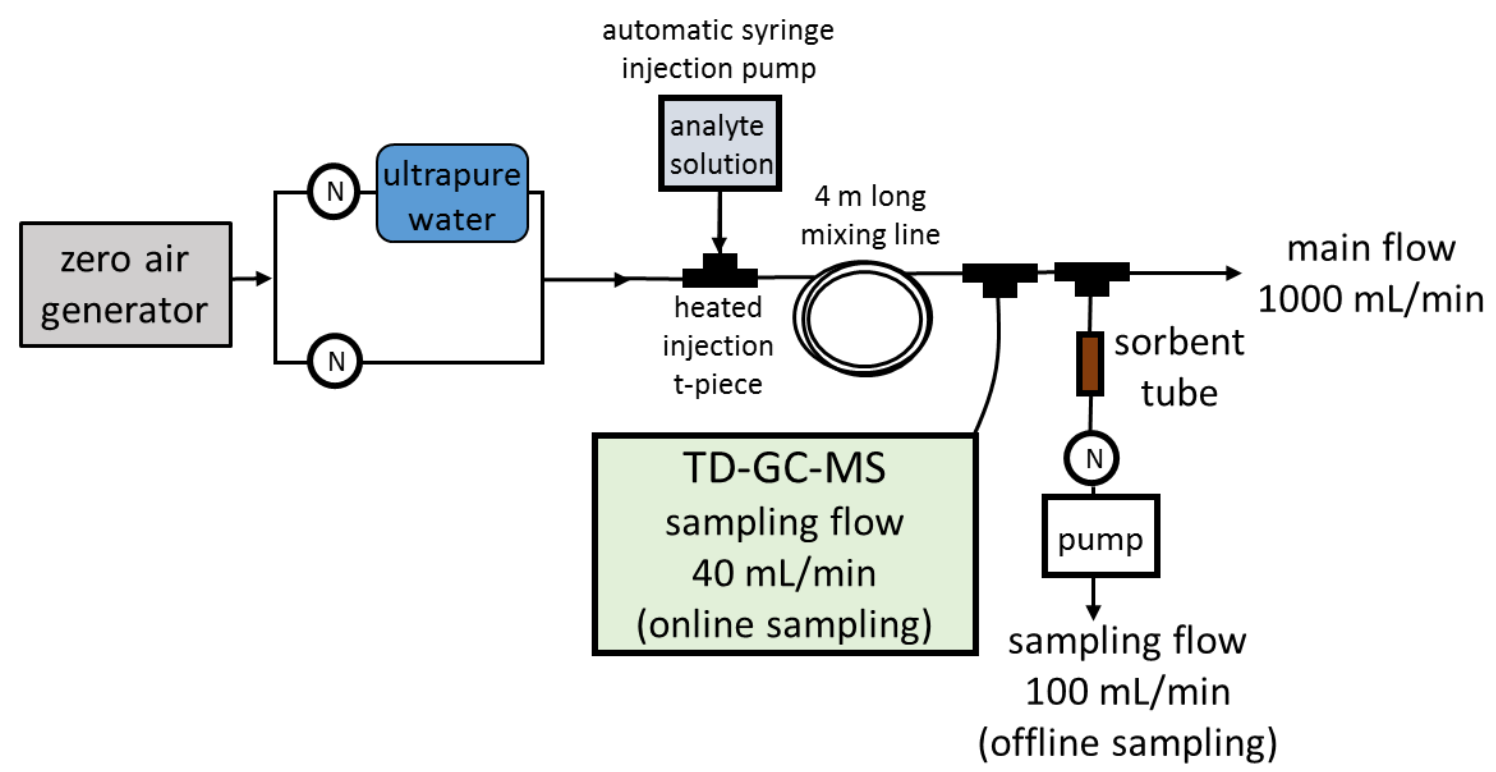

Figure S2. Schematic illustration of the experimental setup used for the comparison of online and offline mode TD-GC-MS sampling and analysis. The analyte solution was injected at a flow rate of $60 \mu \mathrm{L} / \mathrm{h}$, the injection t-piece was heated to $60 \pm 5{ }^{\circ} \mathrm{C}$ and the mixing line was a $4 \mathrm{~m}$ long Teflon tubing (i.d. $1 / 8$ in.). In the online TD-GC-MS mode, the sampling line length from the t-piece to the instrument inlet port was approximately $2 \mathrm{~m}$ Teflon tubing (i.d. 1/16 in.). Sampling time with both sampling modes was 30 min.

\section{TEXT S1. Expanded measurement uncertainty}

The expanded measurement uncertainty (U) was estimated from partial uncertainties of the procedures by following ACTRIS (Aerosol Clouds Trace gases Research InfraStructure) guidelines (ACTRIS, 2018). The U was estimated separately for two analytical procedures: i) offline sorbent tube sampling of ambient air followed by TD-GC-MS analysis and ii) offline sorbent tube sampling of emissions from a branch enclosure cuvette followed by TD-GC-MS analysis.

The combined standard uncertainty (total uncertainty, $u \chi_{\text {total }}$ ) includes both the random and systematic errors affecting the measurements. In this work, the $u \chi_{\text {total }}$ was calculated for both procedures i) and ii) by using Eq. (S1):

$u x_{\text {total }}^{2}=u x_{\text {prec }}^{2}+u x_{\text {stdprep }}^{2}+u x_{\text {vol }}^{2}+u x_{\text {int }}^{2}+u X_{\text {rec }}^{2}$,

where $u \chi_{\text {prec }}$ is the precision component taking into account random errors, $u \chi_{\text {stdprep }}$ is the uncertainty due to calibration standard preparation, $u X_{\mathrm{vol}}$ is the component descriptive of systematic errors in the sample volume determination, $u X_{\text {int }}$ is the systematic integration error, and $u \chi_{\text {rec }}$ is the recovery component taking into account the losses in sampling lines and/or cuvette.

The $u X_{\text {prec }}$ was calculated by following Eq. (S2):

$$
u x_{\text {prec }}^{2}=\left(x_{\text {sample }} * \sigma_{\text {series }}^{\text {rel }}\right)^{2}+\left(\frac{x_{\text {LOD }}}{3}\right)^{2},
$$

where $\mathcal{X}_{\text {sample }}$ is the concentration of the analyte, $\sigma_{\text {series }}^{r e l}$ is the intermediate precision expressed as relative standard deviation and $x_{\text {LOD }}$ is the limit of detection (LOD) value. The intermediate precision was obtained 
from analysing standard samples $(n=22)$ during 4.5 months period (Section 2.3.5). The $x_{\text {LOD }}$ was determined by analysing multiple blank sorbent tubes $(\mathrm{n}=10)$, and then by calculating the standard deviation of peak area in blanks and by multiplying the standard deviation by three.

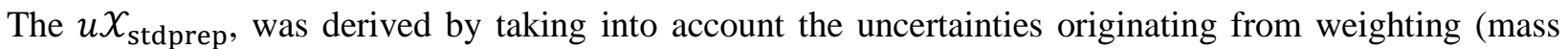
balance error), pipetting (volumetric pipette error) and diluting (volumetric flask error) the standard compounds. The $u \chi_{\text {stdprep }}$ was eventually calculated by setting a $5 \%$ uncertainty, as in Hellen et al. (2002), for all the analytes included in this work. This was considered as an upper estimate for the calibration standard preparation uncertainty.

The $u X_{\mathrm{vol}}$ was estimated based on the uncertainty of the offline sampling by estimating the collective uncertainty related to sampling flow rate and sampling time. In this work, the $u \chi_{\text {vol }}$ for all compounds was derived by using a set $5 \%$ uncertainty. This was considered as being an upper estimate for the sampling volume uncertainty.

The $u X_{\text {int }}$ was obtained by integrating the peak areas in such a way that a definite overestimation of the peak area $\left(A_{\max }\right)$ and underestimation of the peak area $\left(A_{\text {min }}\right)$ were made, similar as shown in ACTRIS, 2018. The potential error in peak area integration $\left(u A_{\text {int }}\right)$ was then obtained by using Eq. (S3), which gives a conservative estimate of the error (ACTRIS, 2018). This was then converted to respective analyte concentrations to obtain $u X_{\text {int }}$.

$$
u A_{\text {int }}=\frac{A_{\max }-A_{\min }}{2}
$$

The $u X_{\text {rec }}$ was calculated based on the sampling line recovery results by using Eq. (S4):

$u x_{\text {rec }}^{2}=\left(x_{\text {sample }} * \sqrt{\left.\frac{\sum(b i a s)^{2}}{n}\right)}\right)^{2}$,

where $\mathcal{X}_{\text {sample }}$ is the concentration of the analyte, bias is the deviation of the observed relative recovery from the $100 \%$ recovery and $n$ is the number of different measurements. The recovery results obtained with the $1 \mathrm{~m}$ long ozone removal inlet at two different relative humidity $(\mathrm{RH})$ levels $(\mathrm{RH}=0 \%$ and $\mathrm{RH}=100 \%)$ were used for the procedure i), whereas the recovery results obtained in the cuvette experiments at flow rates $2.0 \mathrm{~L} / \mathrm{min}$ and $6.7 \mathrm{~L} / \mathrm{min}$ were used for the procedure ii) (see Sections 2.3.3 and 3.1.3). These were considered to being representative of real applications. In procedure i), ambient air can be sampled directly via short ozone removal inlet (as in e.g. Hellen et al., 2018). In procedure ii), the sorbent tubes are sampled from the cuvette outlet port, therefore, there is no need for long sampling lines and ozone removal inlet is not needed since the incoming air is zero VOC free air (as in e.g. Hakola et al., 2006), however, the cuvette recovery needs to be considered.

Finally, the expanded measurement uncertainty (U) was calculated by using Eq. (S5):

$U=2 * u x_{\text {total }}=2 *\left(\frac{u x_{\text {total }}}{x_{\text {sample }}} * 100 \%\right)$.

A coverage factor of $\mathrm{k}=2$ was used for providing a level of confidence of $95 \%$ and the uncertainty was finally converted to relative amount to expresses the $U$ in percentage. The expanded measurement uncertainties for both procedures are presented in the main text Table 1.

\section{References}

ACTRIS, 2018. Deliverable 3.17. Updated Measurement Guideline for NOx and VOCs, available at: 
https://www.actris.eu/Portals/46/Documentation/actris2/Deliverables/public/WP3_D3.17_M42.pdf?ver=2 018-11-12-143115-077. (last access:27 March 2020).

Hellén, H., Hakola, H., Laurila, T., Hiltunen, V., and Koskentalo, T.: Aromatic hydrocarbon and methyl tert-butyl ether measurements in ambient air of Helsinki (Finland) using diffusive samplers, Sci. Tot. Environ., 298, 55-64, 2002.

Hellén, H., Praplan, A. P., Tykkä, T., Ylivinkka, I., Vakkari, V., Bäck, J., Petäjä, T., Kulmala, M., and Hakola, H.: Long-term measurements of volatile organic compounds highlight the importance of sesquiterpenes for the atmospheric chemistry of a boreal forest, Atmos. Chem. Phys., 18, 13839-13863, doi:10.5194/acp-18-13839-2018, 2018.

Hakola, H., Tarvainen, V., Bäck, J., Ranta, H., Bonn, B., Rinne, J., and Kulmala, M.: Seasonal variation of mono- and sesquiterpene emission rates of Scots pine, Biogeosciences, 3, 93-101, doi:10.5194/bg-3-932006, 2006.

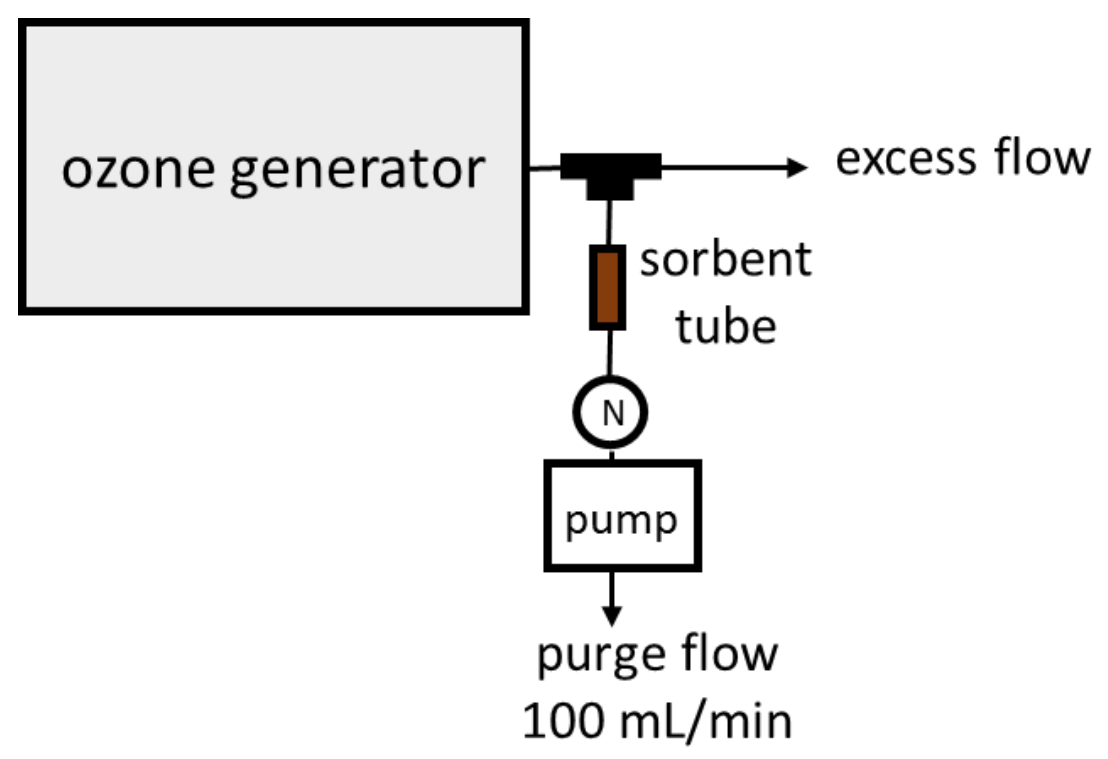

Figure S3. Illustration of the experimental setup used for studying of the compound stability in sorbent tube upon ozone exposure. The ozone generator was used to produce either $\mathrm{O}_{3}=0 \mathrm{ppb}$ or $\mathrm{O}_{3}=40 \mathrm{ppb}$ concentrations. The analyte amounts in sorbent tube were in the range of 40-200 ng. The purge volume was between $0-24 \mathrm{~L}$. 


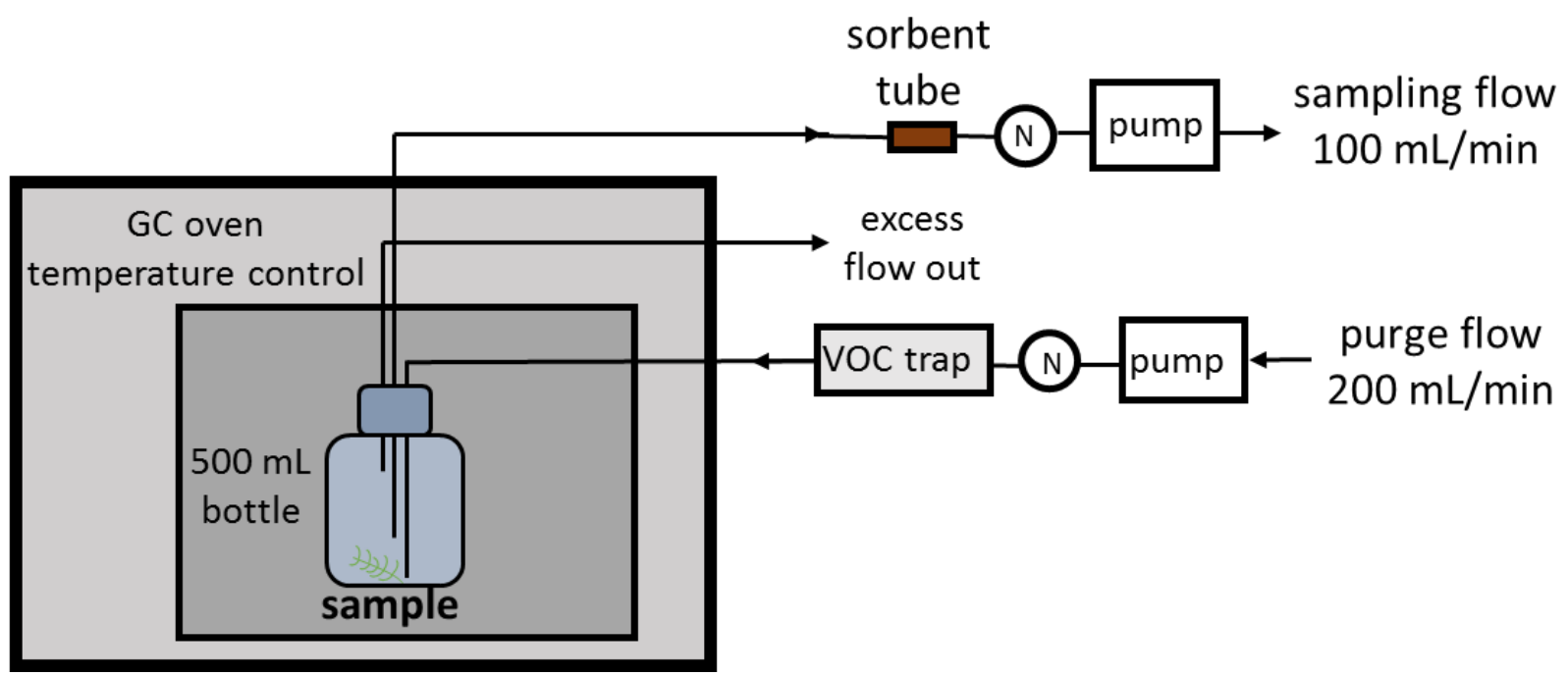

Figure S4. Illustration of the experimental setup used for the purge-and-trap type of headspace extraction of the pine needles and spruce twigs. The samples were placed inside a $500 \mathrm{~mL}$ glass bottle, purified air (active carbon cartridge for VOC trapping) was passed into the bottle and the sorbent tube sample was taken from one outlet line (the other outlet line was exhaust for excess flow). The glass bottle was heated in 5-10 ${ }^{\circ} \mathrm{C}$ steps from room temperature to $70{ }^{\circ} \mathrm{C}$. 

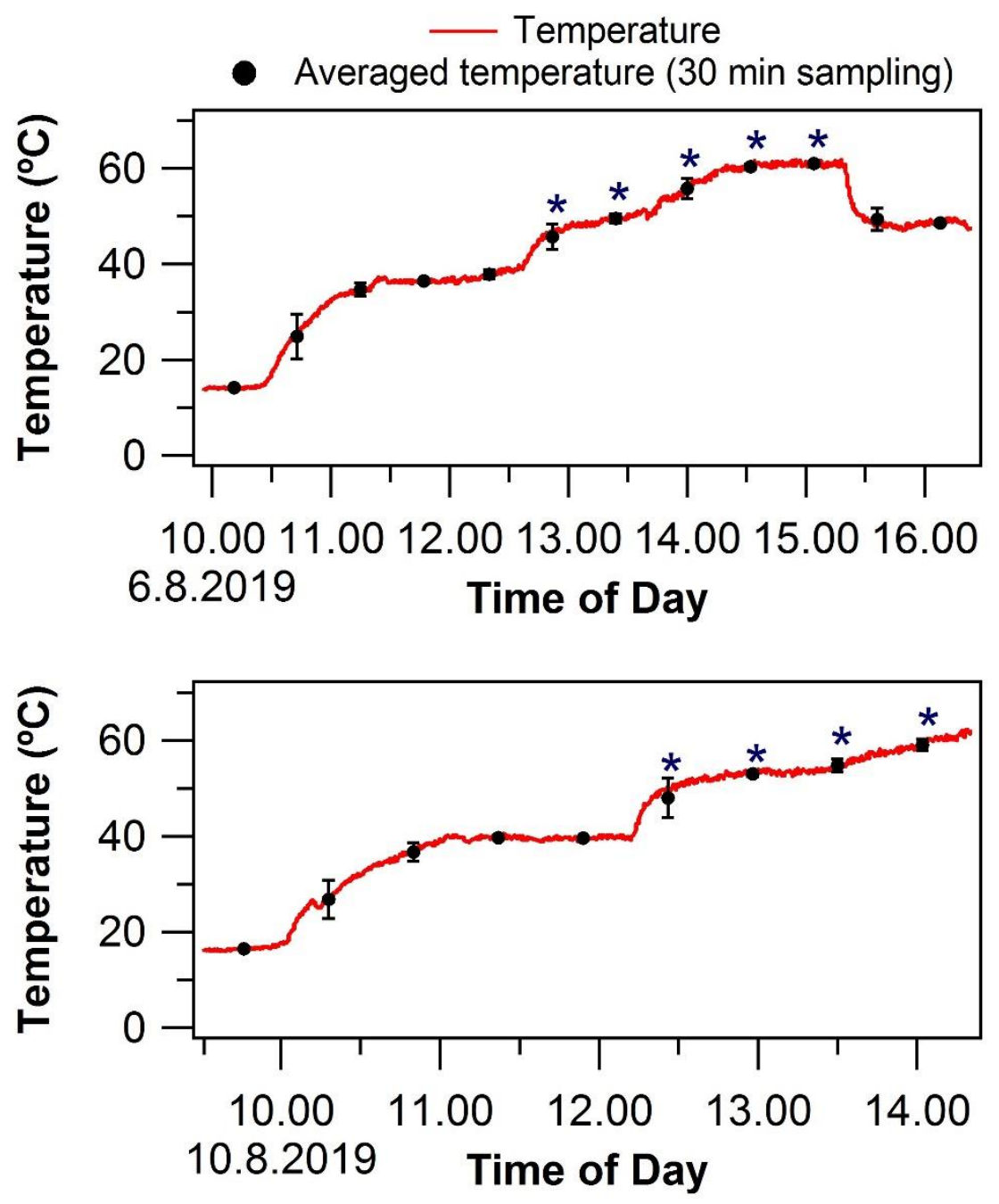

Figure S5. Cuvette inside temperature during the heating cycle on the different sampling dates of branch enclosure emission experiments. The average ( \pm standard deviation) temperature corresponding to the 30 min offline sorbent tube sampling times are plotted on mid-point of sampling. The asterisk points indicate times during which the cuvette was covered with aluminium foil. 


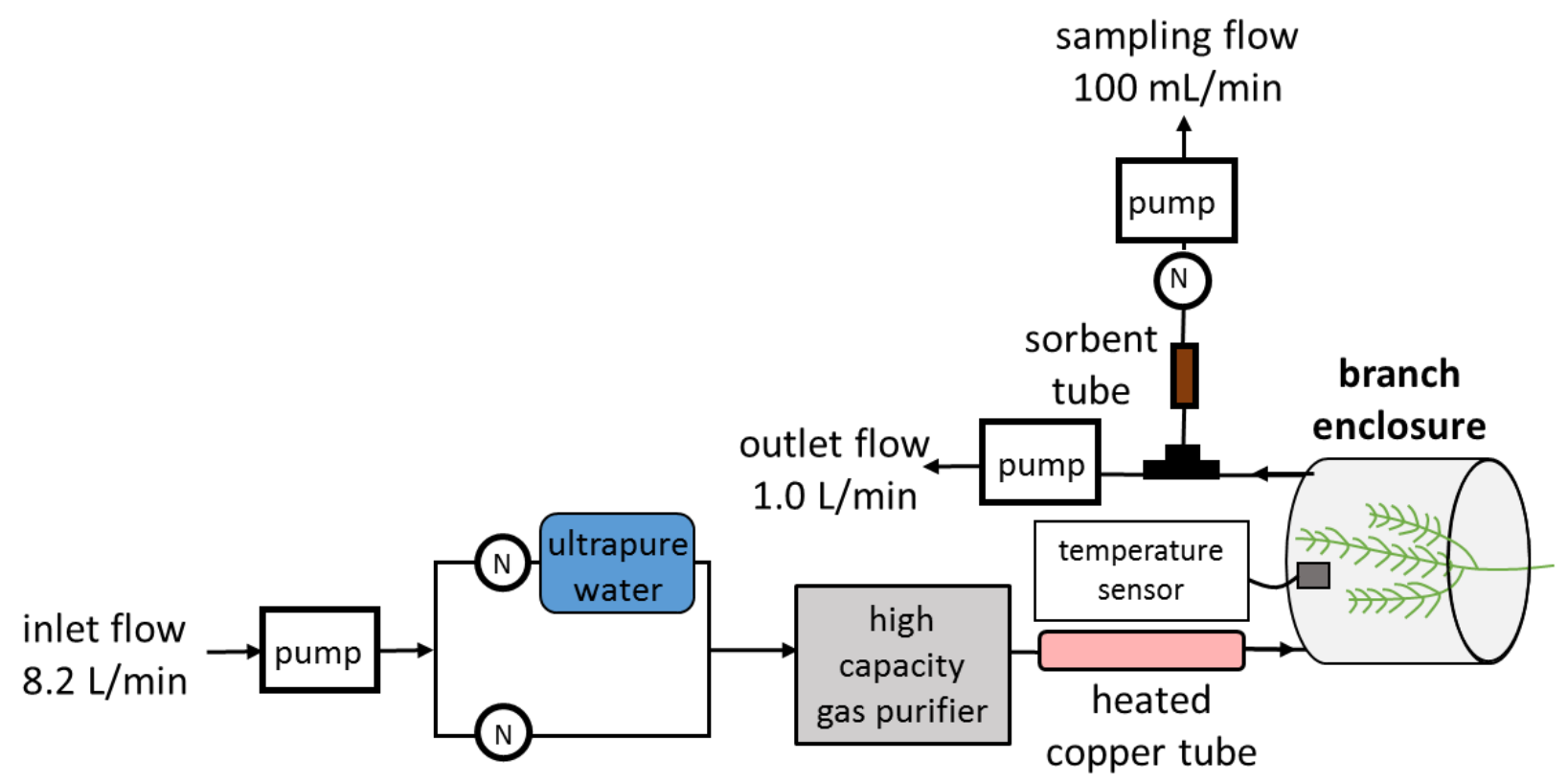

Figure S6. Schematic illustration of the setup used for branch enclosure emission measurements. The schematic presented here corresponds to the setup used on $6^{\text {th }}$ of August, 2019 when the offline sorbent tube sampling was performed from a bypass line. On $10^{\text {th }}$ of August, 2019 the offline sorbent tube sampling (at $100 \mathrm{~mL} / \mathrm{min}$ for $30 \mathrm{~min}$ ) was performed directly from the cuvette outlet. 


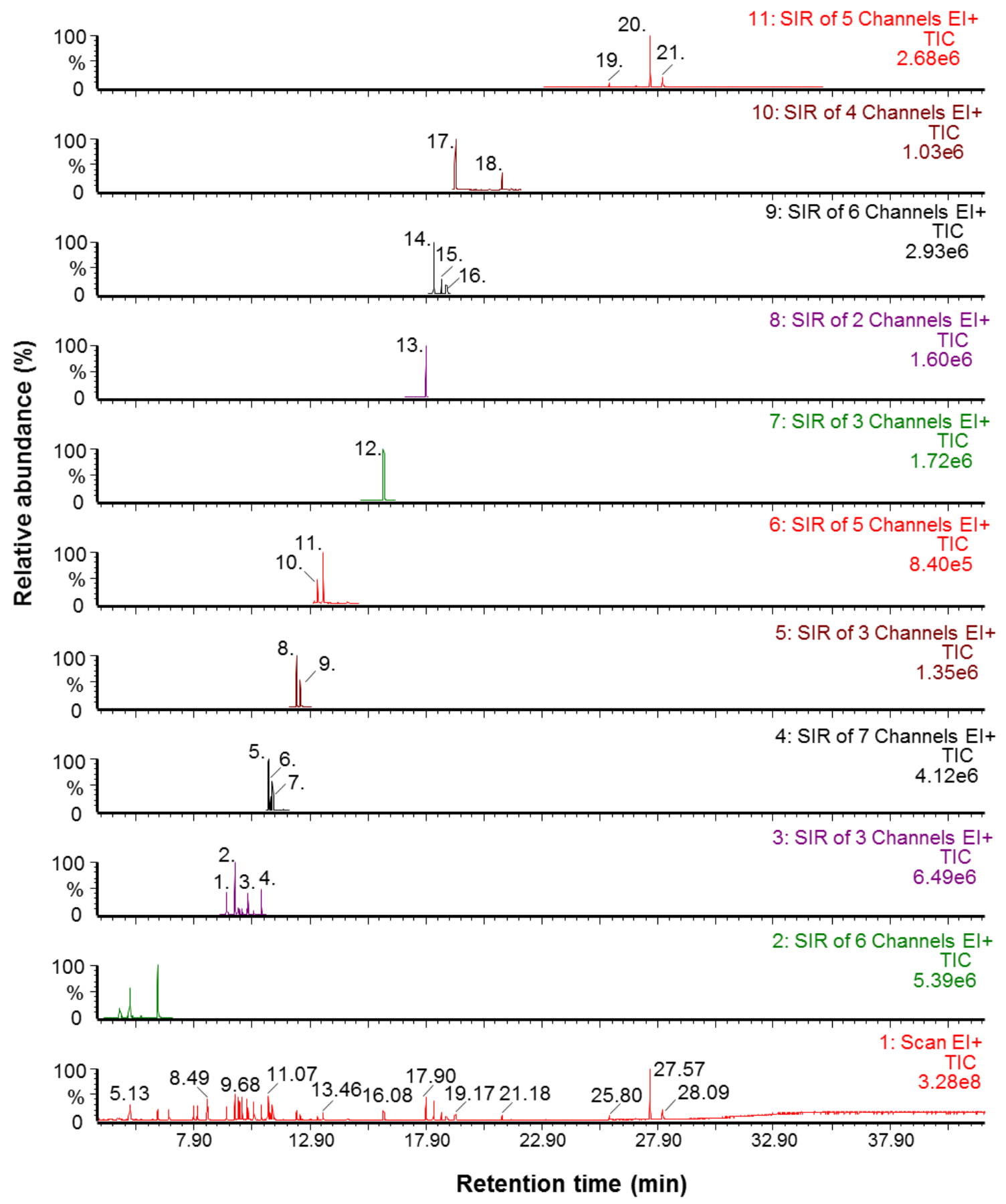

Figure S7. TD-GC-MS total ion chromatogram (TIC, bottom row 1) and selected ion recording (SIR, 211) chromatograms of a standard solution analysis ( $c=10-50 \mathrm{ng}$ in sorbent tube). Analysis conditions are presented in Table S2 (TD-GC-MS1). Peak identification: 1. $\alpha$-pinene, 2. camphene, 3. $\beta$-pinene, 4. 3carene, 5. p-cymene, 6. limonene, 7. 1,8-cineol, 8. terpinolene, 9. linalool, 10. 4-AMCH, 11. nopinone, 12. bornylacetate, 13 . longicyclene, 14 . isolongifolene, 15. $\beta$-caryophyllene, 16 . $\beta$-farnesene, 17 . $\alpha$-humulene, 18. caryophyllene oxide, 19. cembrene, 20. ent-kaurene and 21. 3-MA. For abbreviations see main text Table 1 or Table S1. 


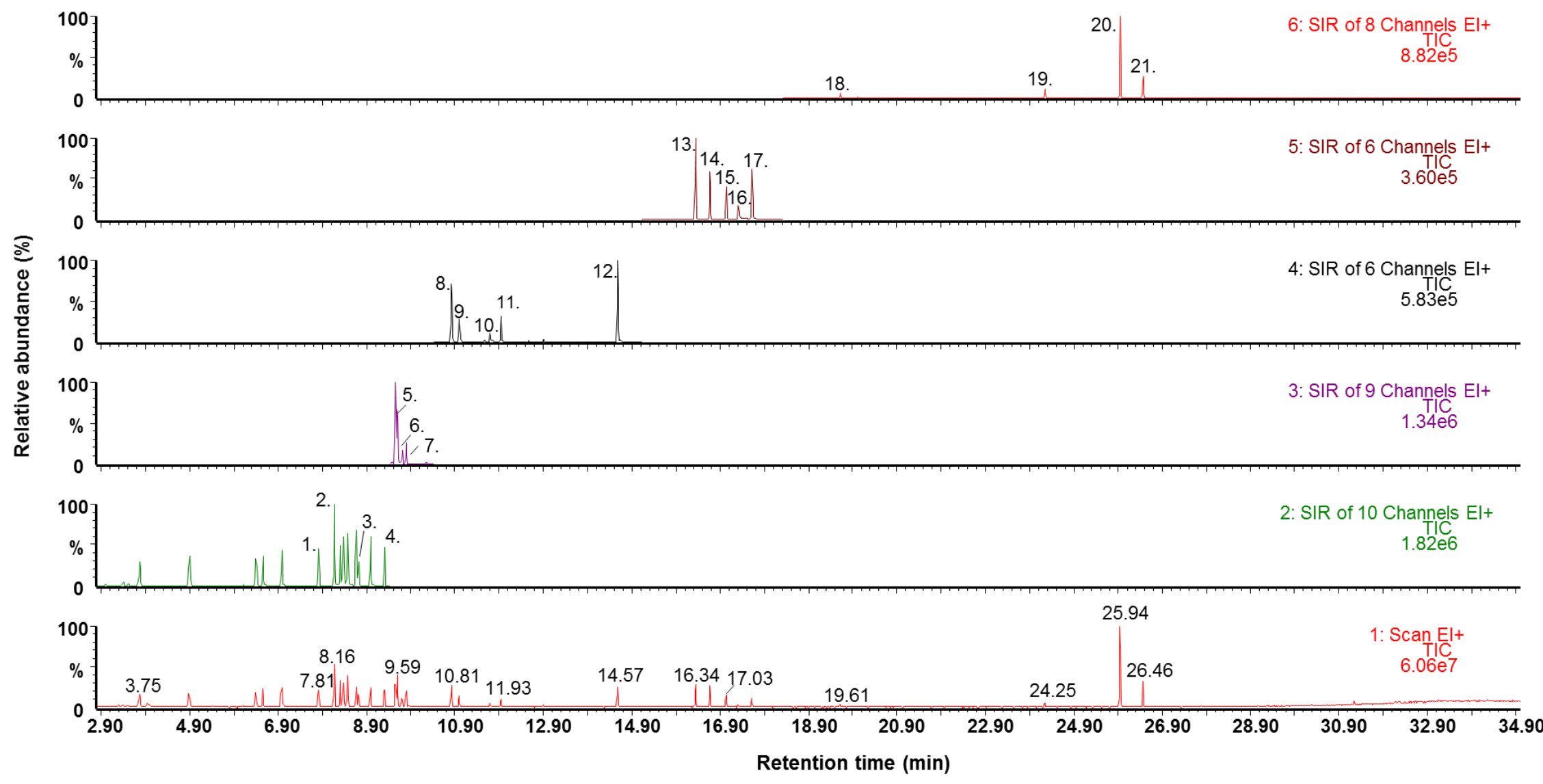

Figure S8. TD-GC-MS total ion chromatogram (TIC, bottom row 1) and selected ion recording (SIR, 2-6) chromatograms of a standard solution analysis ( $c=10-50 \mathrm{ng}$ in sorbent tube). Analysis conditions are presented in Table S2 (TD-GC-MS2). Peak identification: 1. $\alpha$-pinene, 2. camphene, 3. $\beta$-pinene, 4. 3-carene, 5. p-cymene, 6. limonene, 7. 1,8-cineol, 8. terpinolene, 9. linalool, 10. 4-AMCH, 11. nopinone, 12. bornylacetate, 13. longicyclene, 14. isolongifolene, 15. $\beta$-caryophyllene, 16. $\beta$-farnesene, 17. $\alpha$-humulene, 18. caryophyllene oxide, 19 . cembrene, 20. ent-kaurene and 21. 3-MA. For abbreviations see main text Table 1 or Table S1. 


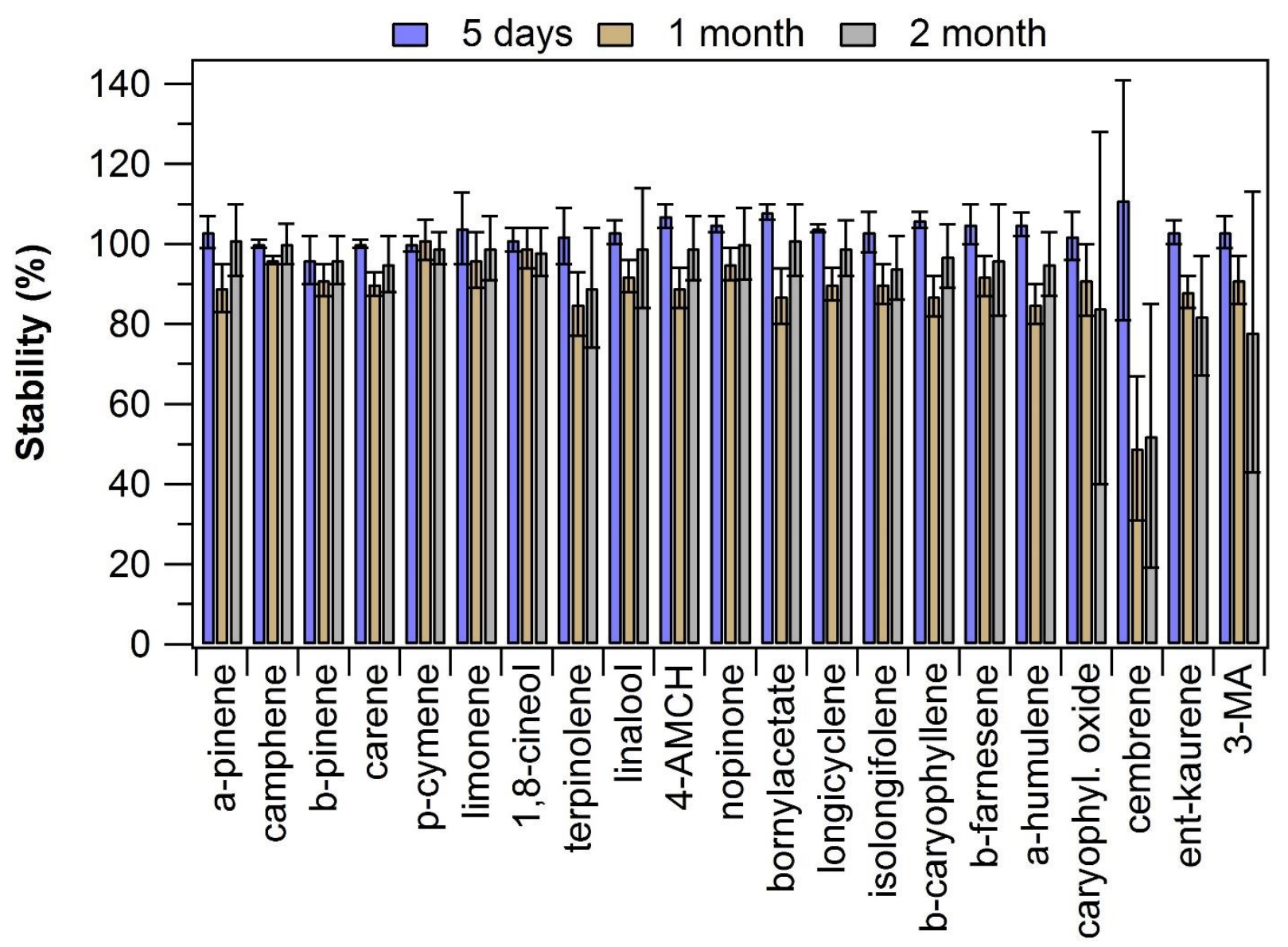

Figure S9. Stability of the analytes in sorbent tube ( $c=40-200 \mathrm{ng}$ ) during storage ( 5 days, 32-33 days and 62 days) in the dark at $4^{\circ} \mathrm{C}$. The error bars represent reproducibility $(n=2-6)$. 


\section{TEXT S2. Comparison between online and offline TD-GC-MS sampling}

\section{S2.1 Overview of comparison parameters and conditions}

As outlined in the main text Section 2.3.4, online sampling mode was compared to offline sampling mode with TD-GC-MS1. The experiments were done as shown in the schematic setup shown in Fig. S2. The sampling flow rate was $40 \mathrm{~mL} / \mathrm{min}$ for $30 \mathrm{~min}$ in online mode sampling (total volume $1.2 \mathrm{~L}$ ). The online sampling was performed via an empty stainless-steel tube directly into the Tenax TA/Carbopack cold trap (Fig. S10). In the offline sorbent tube sampling, the flow rate was $100 \mathrm{~mL} / \mathrm{min}$ for $30 \mathrm{~min}$ (sampling volume $3.0 \mathrm{~L}$ ). The online and offline mode sampling times were harmonized. The analyte concentrations were typically in the level of 9.3-13.2 $\mu \mathrm{g} / \mathrm{m}^{3}$ for MTs, $8.4-13.8 \mu \mathrm{g} / \mathrm{m}^{3}$ for SQTs, $1.7-11.4 \mu \mathrm{g} / \mathrm{m}^{3}$ for DTs and 8.8 $9.9 \mu \mathrm{g} / \mathrm{m}^{3}$ for other VOCs. The analytes were always injected as a mixture of all compounds.

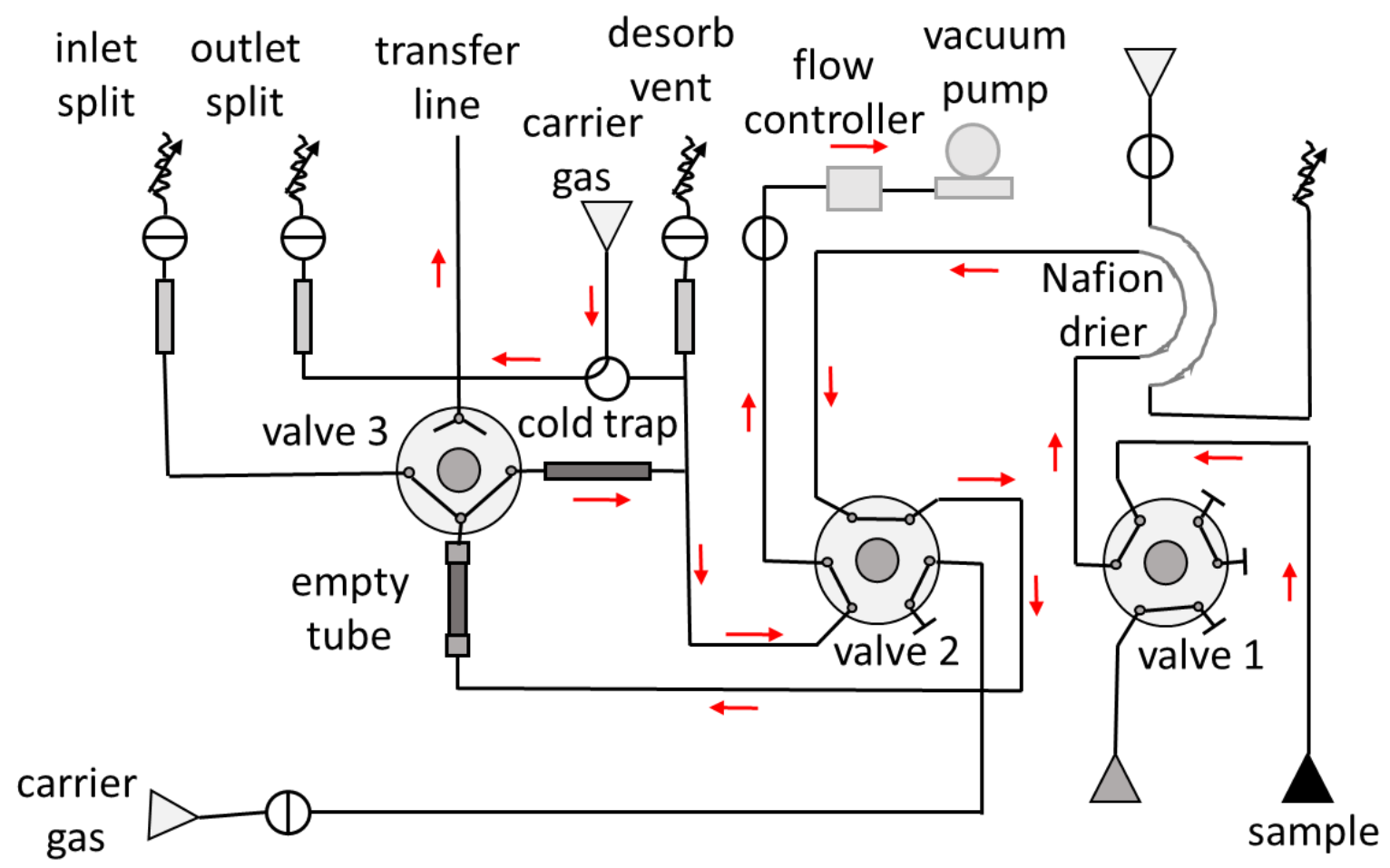

Figure S10. Schematic diagram of the conventional online sampling mode in the TD (adapted from instrument user's guide). The red arrows indicate the online sampling mode flow directions. In the TD unit used in this study, the Nafion drier was replaced with a ca. $10 \mathrm{~cm}$ long Teflon tubing (i.d. 1/16 in.).

The TD-GC-MS analysis conditions were otherwise exactly the same with both sampling modes (see Table S2), with the exception that in the online mode there was no primary desorption step. In online sampling mode, the sample is drawn in through an empty tube held at room temperature and directly focused onto the cold trap. Thus, there is theoretically no need for primary desorption. In online sampling mode, the instrument software allows only an option to control the secondary desorption.

The different sampling mode results were compared to each other based on recoveries as shown in equation:

$$
\text { Recovery }=\frac{\text { analyte concentration in online mode }\left(\mu \mathrm{g} / \mathrm{m}^{3}\right)}{\text { analyte concentration in offline mode }\left(\mu \mathrm{g} / \mathrm{m}^{3}\right)} * 100 \%
$$




\section{S2.2 Initial trials and problem identification}

It was observed that some of the analytes were lost in the online sampling mode. In the TD unit, an empty sorbent tube was used in the online mode to connect the online sampling box to the main TD (see Fig. S10). This empty tube has a high surface area compared to the other TD parts in the sample path and therefore is a probable source of poor recoveries. To test the losses into the empty stainless-steel tube used in online sampling, the empty tube was heated after the sampling to $300{ }^{\circ} \mathrm{C}$ and compounds desorbed were analyzed. In this re-analysis of the empty tube, multiple different compounds could be detected in surprisingly high amounts. For example, $\beta$-farnesene was observed in the empty tube in such a high amounts, that it would explain approximately $44 \%$ of the amount lost during online sampling. Ent-kaurene and cembrene were observed in the empty tube in amounts that would explain roughly $2 \%$ and $12 \%$ of the lost fraction, respectively. For caryophyllene oxide, the corresponding portion was estimated to be $14 \%$. Of the compounds that were completely lost (or below LOQ) in the online sampling, only 3-MA could not be detected in the empty tube run. If a clean sorbent tube was analyzed after online sampling instead of the empty tube used in the online sampling, no compounds were detected. Since the blank sorbent tube run after the online analysis did not show any analyte peaks, and yet the following empty tube analysis showed analyte peaks, it indicates that the lost analyte fraction is most likely lost partially into the empty tube and partially to TD parts/lines prior to the heated valve (Fig. S10).

In Fig. S11 are shown the recoveries obtained with three different empty stainless-steel (SS1-SS3) tubes used in online sampling mode. Overall, the recoveries of most MTs were acceptable with all three tubes (on average $96 \pm 6 \%$ ), except linalool recovery was fairly poor with two of the tubes $(\approx 66 \%)$ and with one tube linalool amount was below LOQ (Fig. S11). For almost all other analytes, mixed results were obtained with the different empty tubes tested. Sesquiterpenes (excluding $\beta$-farnesene) recoveries were satisfactory with two of the tubes tested $(84 \pm 10 \%)$, but with one of the tubes the SQTs recoveries were extremely poor $(<25 \%)$. Most notably, diterpenes were not observed in the online samples with any of the tubes tested. The empty tube cleaning (ultrasonication in methanol for $60 \mathrm{~min}$ and drying at $300{ }^{\circ} \mathrm{C}$ for $30 \mathrm{~min}$ ) did not improve the online sampling performance. With some of the compounds, the recovery improved in consecutive repetitions, e.g. with linalool, bornylacetate and $\alpha$-humulene the recoveries increased from 50 to $87 \%$, from 67 to $107 \%$ and from $41 \%$ to $105 \%$, respectively (between the first and second repetition).

Based on these results it can be concluded that $\beta$-farnesene, all DTs and caryophyllene oxide were commonly lost in significant amounts in online sampling. These compounds were lost at least partially into the inner surface of the empty stainless-steel tubes used for connecting online sampling box to the main TD. However, a significant fraction of the losses were not recovered by the re-analysis of the empty tubes, which indicates that those compounds are either totally lost into the tubes or losses are also occurring in the other parts of the TD unit. 


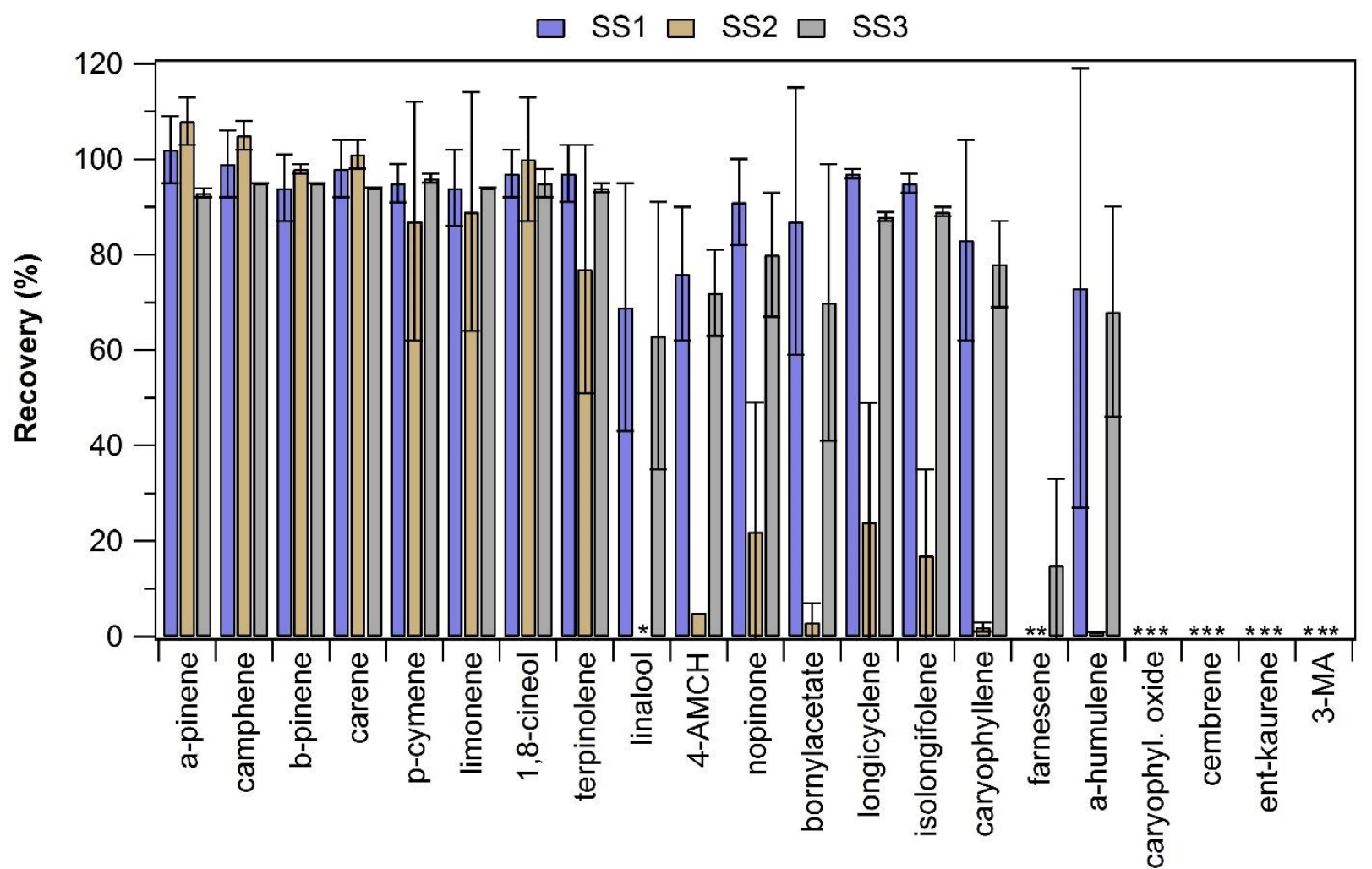

Figure S11. Recoveries obtained with three different empty stainless-steel (SS) tubes tested in online sampling. The error bars represent repeatability $(n=2)$. The empty spaces marked with asterisk are results where the online sampling analyte concentrations were $<\mathrm{LOQ}$.

\section{S2.3 Glass tube in online sampling}

Since poor recoveries were observed with the stainless-steel empty tubes, an empty glass tube (from PerkinElmer Inc., Waltham, MA, USA) was tested in the online sampling mode. In general, the recovery results (Fig. S12) obtained with the empty glass tube were much better when compared to the results obtained with stainless-steel tubes. The recoveries of monoterpenoids and sesquiterpenes were acceptable, on average $85 \pm 6 \%$ and $80 \pm 3 \%$, respectively (Fig. 12). Even $\beta$-farnesene could be detected and the recovery was $85 \pm 2 \%$; a notable improvement to previous online sampling mode results (Fig. S11). Furthermore, with the glass tube, caryophyllene oxide and DTs could be detected, however, the recoveries were still fairly poor (on average from $19 \pm 16 \%$ to $81 \pm 66 \%$ ). With those compounds, the recoveries were improving in consecutive repetitions $(n=4)$, e.g. with ent-kaurene from $16 \%$ to $63 \%$ and with cembrene from <LOQ to $156 \%$. Overall, the results obtained with the glass tube were promising, especially when compared to the results obtained previously with the stainless-steel tubes. 


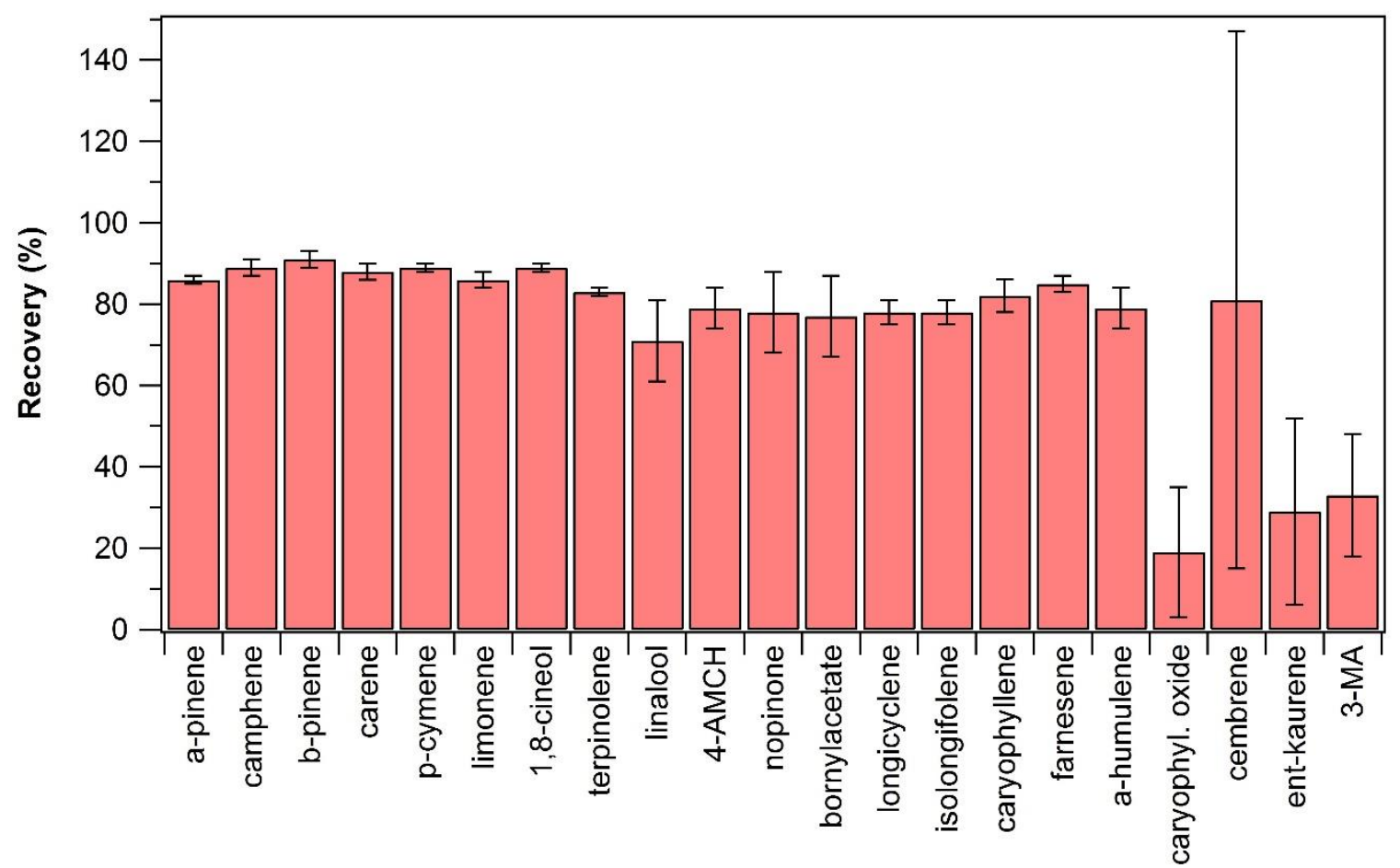

Figure S12. Recovery results obtained when empty glass tube was used in online sampling. The error bars represent repeatability $(n=4)$.

\section{S2.4 Effect of relative humidity}

The effect of relative humidity $(\mathrm{RH})$ on recoveries was tested with both empty stainless-steel tube and glass tube. Three different RH levels were tested (5\%, $40 \%$ and $70 \%)$. With each RH level, two repetitions were done.

The recovery results for both empty tube materials are shown in Fig. S13. With both tubes, the MTs recovery levels decreased slightly as the $\mathrm{RH}$ increased, e.g. with the stainless-steel tube the recoveries were on average $94 \pm 12 \%, 89 \pm 6 \%$ and $86 \pm 3 \%$ at $\mathrm{RH}=5 \%, \mathrm{RH}=40 \%$ and $\mathrm{RH}=70 \%$, respectively, although the difference in decline is within the standard deviation. With the stainless-steel tube, most sesquiterpenes recoveries stayed fairly constant at different $\mathrm{RH}$ levels $(82 \pm 9 \%$ at $\mathrm{RH}=5 \%, 84 \pm 3 \%$ at $\mathrm{RH}=40 \%$ and $82 \pm 1$ $\%$ at $\mathrm{RH}=70 \%$ ), except with $\beta$-farnesene which had an increasing recovery as the RH increased (Fig. S13a). Clearly, the increased RH level affected positively to the online sampling efficiency of $\beta$-farnesene with the stainless-steel tube. With the empty glass tube, the sesquiterpenes recoveries decreased slightly as the $\mathrm{RH}$ increased, on average from $90 \pm 4 \%$ to $82 \pm 5 \%$ (Fig. S13b). In general, with the glass tube, almost all other compounds showed either slightly decreasing recovery trend or the recoveries stayed fairly constant as the RH increased, except DTs and caryophyllene oxide. These compounds showed higher recoveries as the RH increased (on average recoveries increased from $21 \pm 14 \%$ to $51 \pm 20 \%$, Fig. S13b). Similar trend was noticed with the stainless-steel tube, DTs and caryophyllene oxide recoveries increased from not detected to $15 \pm 17 \%$ as the RH increased (most notably with caryophyllene oxide, Fig. S13a). Collectively, the results indicate that the compound losses in online sampling mode are lower when the sample air RH is higher. 

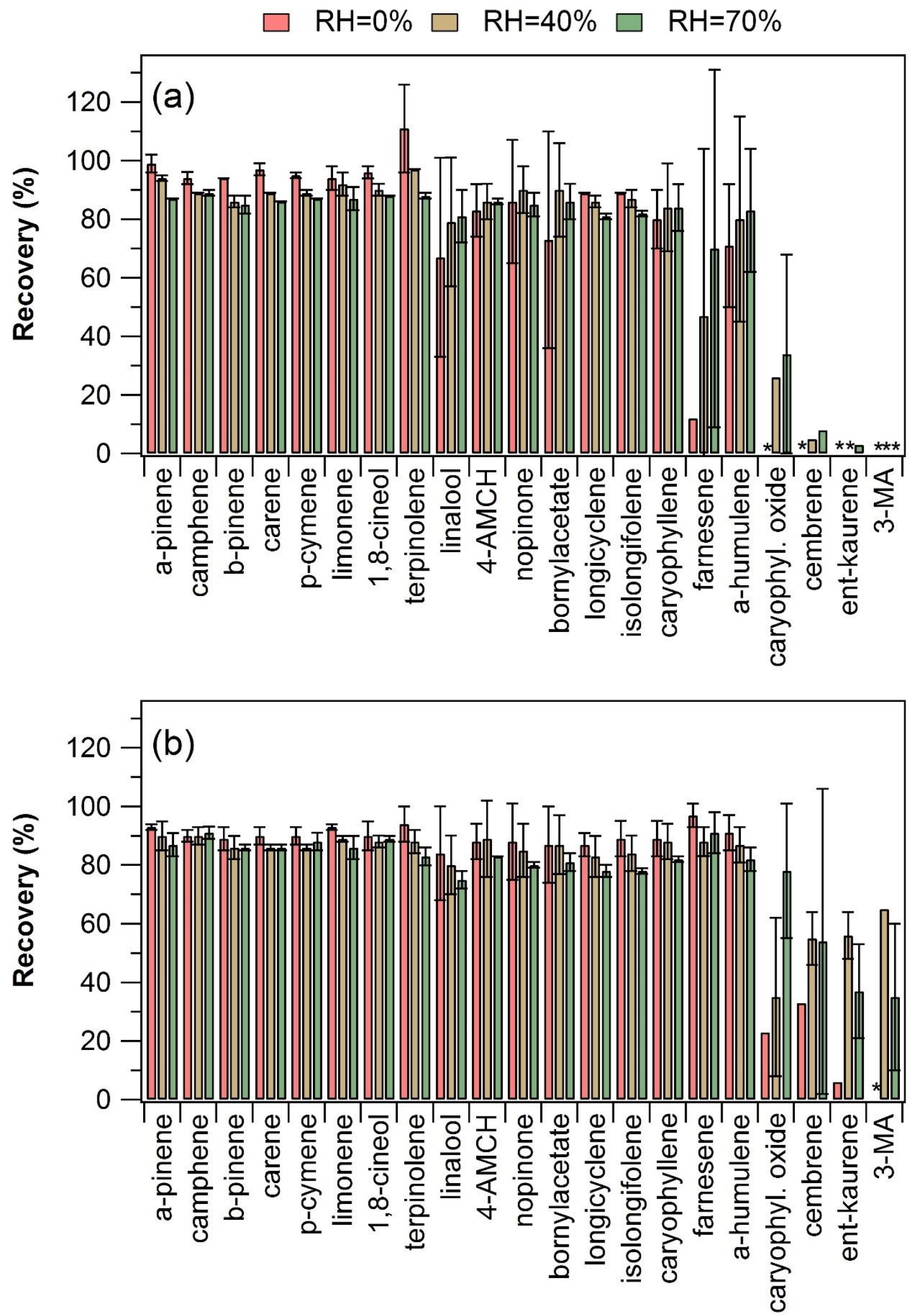

Figure S13. The effect of relative humidity $(\mathrm{RH}=0,40$ and $70 \%)$ on analyte recoveries when using (a) stainless-steel empty tube or (b) glass tube. The error bars represent repeatability $(n=2)$. The empty places marked with asterisk indicate online mode results $<\mathrm{LOQ}$. 


\section{S2.5 TD unit line replacements}

Since a fairly large portion of the losses of some compounds could not be explained by the empty tube accounted losses, some of the TD unit lines were replaced. As presented in Fig. S10, the online sample goes normally through a Nafion drier installment. In our TD unit, this was modified already from the beginning so that the Nafion dryer was replaced with a short piece of Teflon tubing. This setup was now further changed so that the lines between the connections and valves were changed from stainless-steel to Teflon tubing and the lines were made generally shorter. Specifically, the line from sample inlet to valve 1 and the line from valve 1 to valve 2 were replaced (Fig. S10). The other lines could not be easily changed and these were left as such (original stainless-steel tubing).

Unfortunately, the line replacements caused initially a general overall decrease in recoveries (data not shown). During first set of repetitions (with stainless-steel empty tube used in online sampling), even the MTs recoveries were fairly poor (on average $73 \pm 12 \%$ ). In general, the recoveries were roughly on average 10-20\% lower after the TD lines were changed from stainless-steel to Teflon tubing. However, over time when the experiments were repeatedly performed, the recoveries started to improve and eventually reached a similar level as prior to the line changes (Fig. S14). In fact, the recoveries of caryophyllene oxide and DTs were slightly better after the line changes than prior to line changes. It is unknown if the initially observed drop in overall recoveries was caused by some active surfaces in the Teflon line (which became saturated over time) or by potential loose connections upon line changes (connections were open/closed separately a few times to investigate possible leaking).

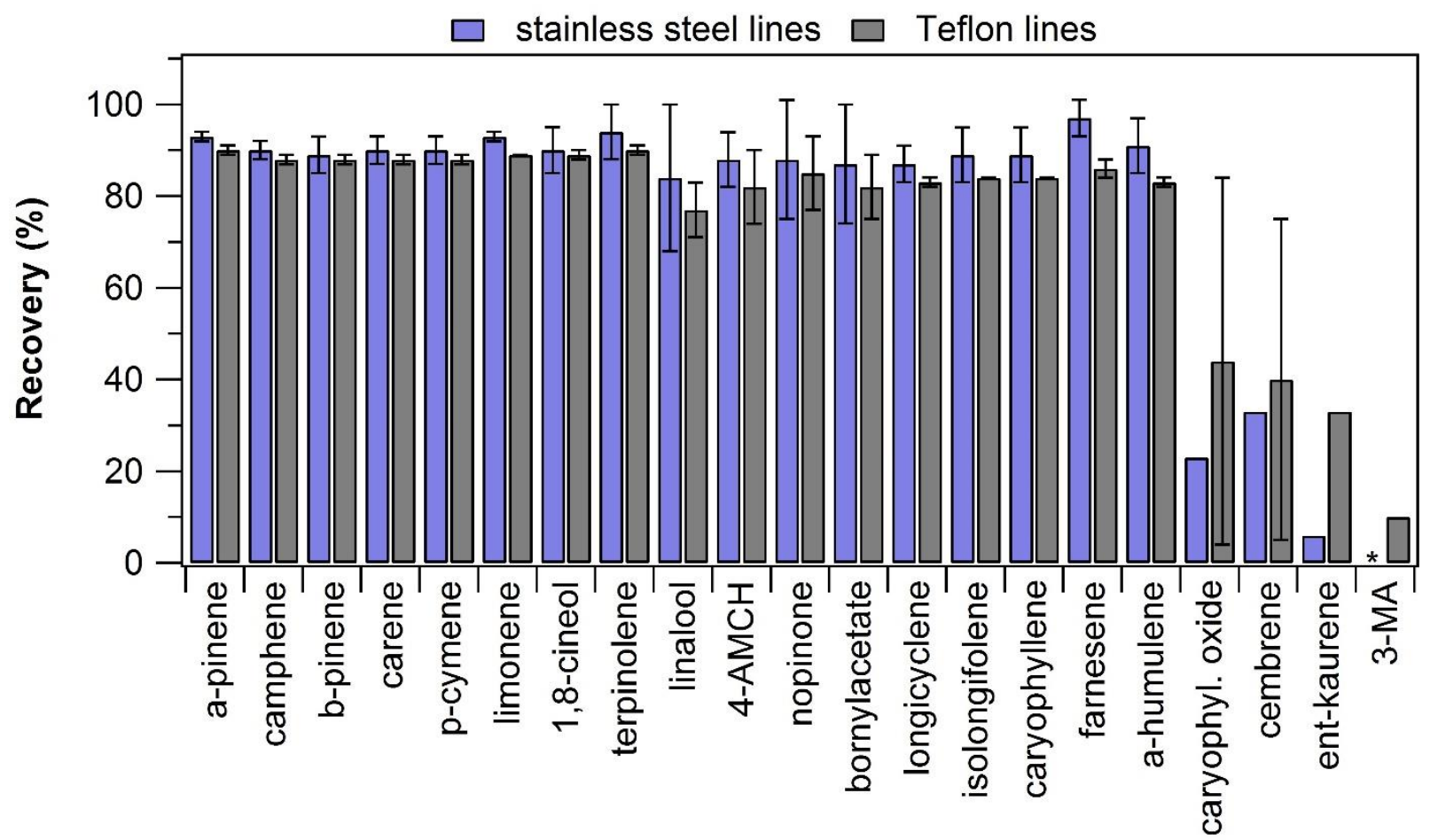

Figure S14. The results obtained after the TD unit line changes from stainless-steel lines to Teflon lines. Experiments were performed at $\mathrm{RH}=0 \%$ by using an empty glass tube in online sampling. Error bars represent repeatability $(n=2)$. The empty spaces marked with asterisk indicate online mode results $<$ LOQ. 


\section{S2.6 Recoveries with an empty glass coated stainless-steel tube}

According to TD-GC-MS manufacturers' recommendation (personal communication), an empty stainlesssteel tube with glass coated inner surface (from PerkinElmer Inc., Waltham, MA, USA ) was tested in online sampling. This glass coated stainless-steel tube was reportedly better in terms of robustness when compared to the plain glass tube. In addition, it was speculated that the glass coated stainless-steel tube might work better in online sampling than the plain glass tube due to slightly higher tube temperature. In online sampling mode, the empty tube is theoretically at room temperature during sampling, however, the upper part of the tube is connected to the heated valve via a fixed metallic tube holder (Fig. S10). Thus, in practice the heat was transferred through the metal parts to the upper part of the tube and the stainless-steel tube was unintentionally slightly heated. Since heat is beneficial for avoiding terpene losses, it was speculated that the difference between the plain glass and glass coated stainless-steel tube might be observable due to the difference in material heat transfer capability.

As can be seen Fig. S15, the recoveries were on a similar level with the glass coated stainless-steel tube and with the previously tested plain glass tube. The speculated improved heat transfer effect did not seem to affect the recoveries in reality. Both empty tubes that had glass inner surface performed generally better than the stainless-steel tube in online sampling. This was especially the case in the recoveries of $\beta$ farnesene, DTs and caryophyllene oxide (Fig. S15).

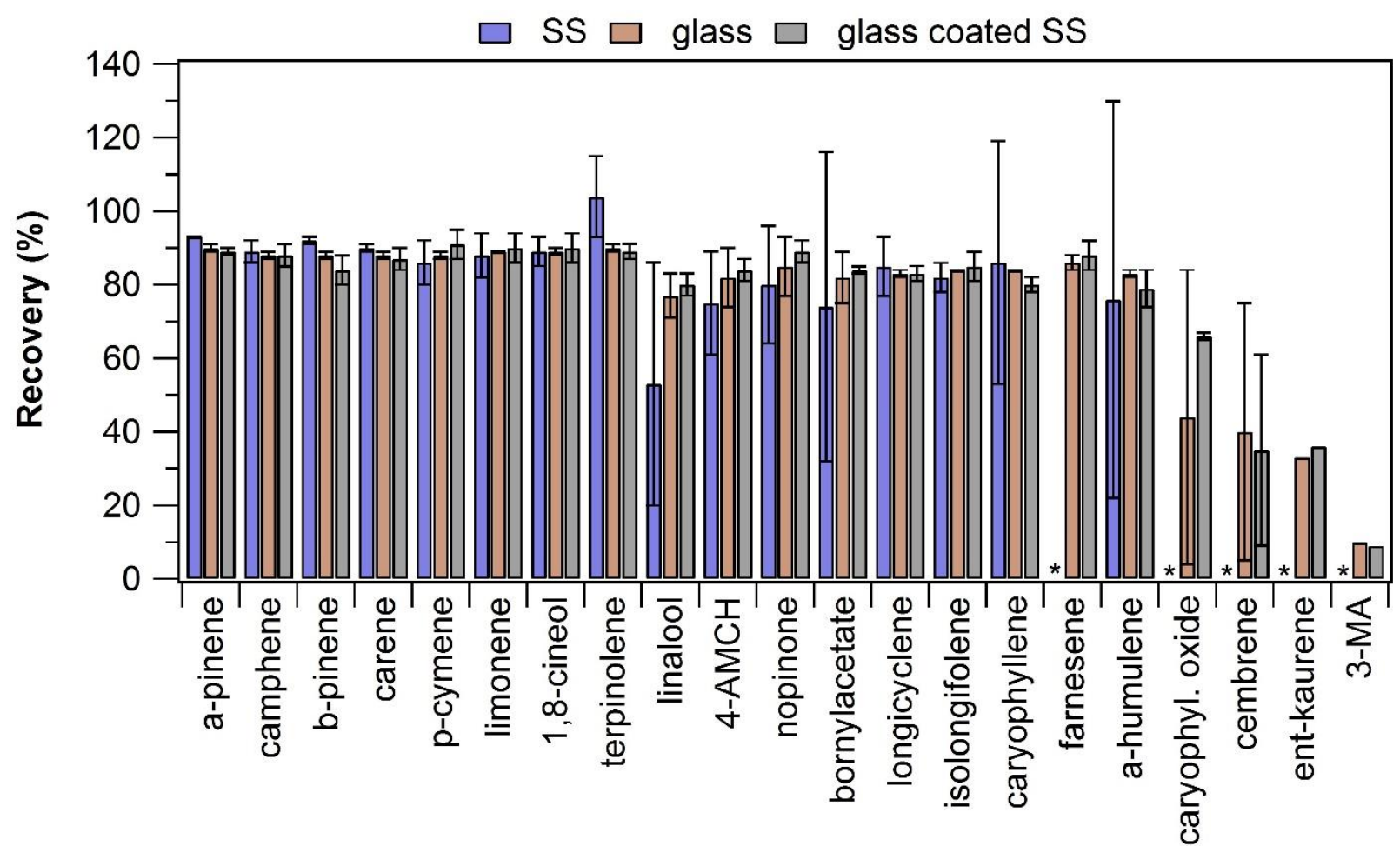

Figure S15. Comparison of the recovery levels obtained when using either stainless-steel (SS), glass tube or glass inner surface coated stainless-steel tube in online sampling at $\mathrm{RH}=0 \%$. The error bars represent repeatability $(n=2)$. The empty spaces marked with asterisk indicate online mode results $<\mathrm{LOQ}$.

The effect of RH on recoveries from the glass coated stainless-steel tube (Fig. S16) was similar as previously with the plain glass tube (Fig. S13b). The recoveries of DTs and caryophyllene oxide increased as the RH increased. It seems that if the RH is high enough, the online sampling agrees fairly well with the offline sampling results. 


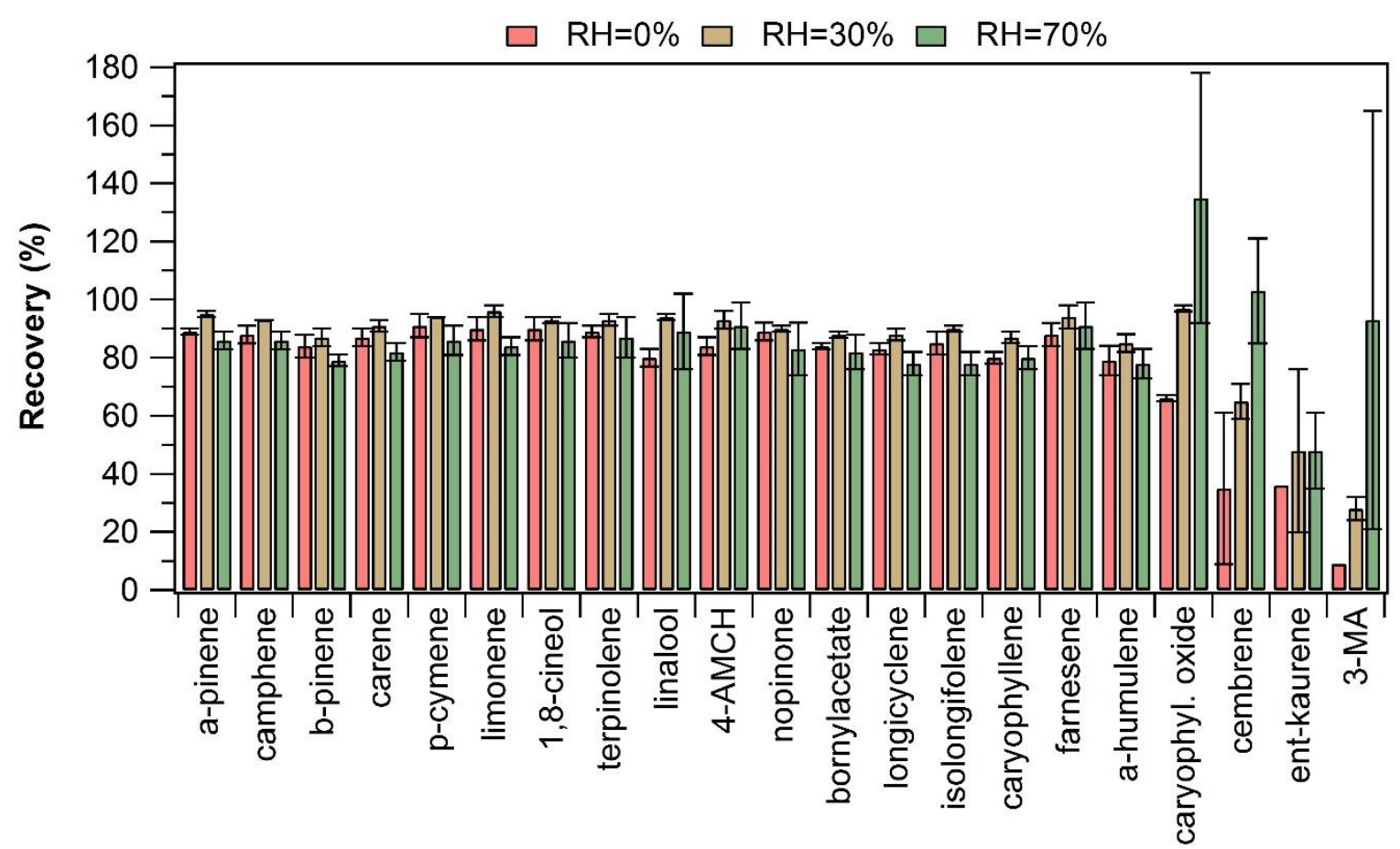

Figure S16. Effect of relative humidity $(\mathrm{RH})$ on recoveries when the glass coated empty stainless-steel tube was used in online sampling. The error bars represent repeatability $(n=2-3)$.

\section{S2.7 Summary of results}

The comparison of results obtained by online and offline mode sampling revealed that some compounds were partially lost in the online sampling. In general, the losses were compound specific and mainly restricted to $\beta$-farnesene, caryophyllene oxide and DTs. Monoterpenoids and other sesquiterpenes results agreed fairly well between both sampling modes. The main parameters observed to affect the recoveries of SQTs and DTs were sample air relative humidity and the material of the empty tube used in online sampling (or materials in general in the sample air path). Empty tubes made of glass performed better than stainlesssteel tubes in online sampling. When the glass tubes were used in online sampling, $\beta$-farnesene had acceptable recovery $(\approx 87 \%)$. Also, with the glass tubes diterpenes and caryophyllene oxide could be detected, and at high $\mathrm{RH}$ level the recoveries were on average satisfactory $(\approx 64 \%)$, although the uncertainties in results were substantial. With stainless-steel tubes, the recoveries of DTs were poor $(<35$ $\%$ ) even at the highest RH level.

Our tentative results indicated that in long-term use of online sampling the recoveries may stabilize and improve. We had on maximum four consecutive repetitions, which showed improvement in recoveries of some of the compounds. However, this should be studied further in future with more repetitions.

In summary, online TD-GC-MS sampling and analysis can be used for the quantification of monoterpenoids and sesquiterpenes in air samples. However, the quantification of DTs and caryophyllene oxide can be challenging. Based on the results presented here, it is recommended to use empty tubes which have glass inner surface in online sampling. In addition, the sample air relative humidity should be controlled (if possible) and monitored. Since the relative humidity seemed to have an effect on online sampling performance of DTs and caryophyllene oxide, it might be necessary to derive correction equation experimentally to harmonize the results if the RH changes in sample air. 

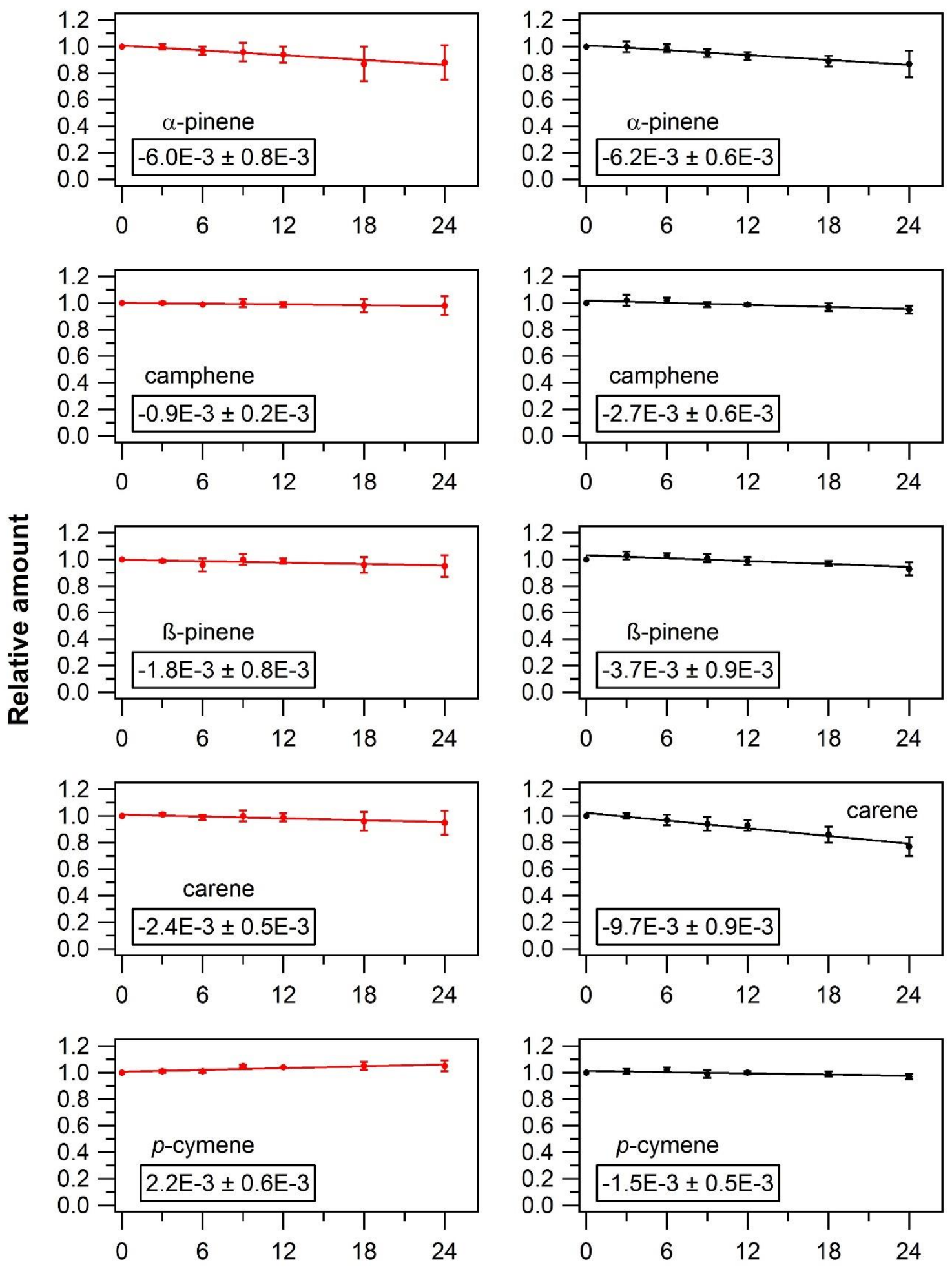

Purge volume (L)

Figure S17. Results from the ozone exposure experiments. The left (red) and right (black) panel plots are from the $\mathrm{O}_{3}=0 \mathrm{ppb}$ and $\mathrm{O}_{3}=40 \mathrm{ppb}$ experiments, respectively. The values embedded into the plots are the slopes ( \pm uncertainty) of the linear regression fits. The error bars represent reproducibility $(n=3)$. 

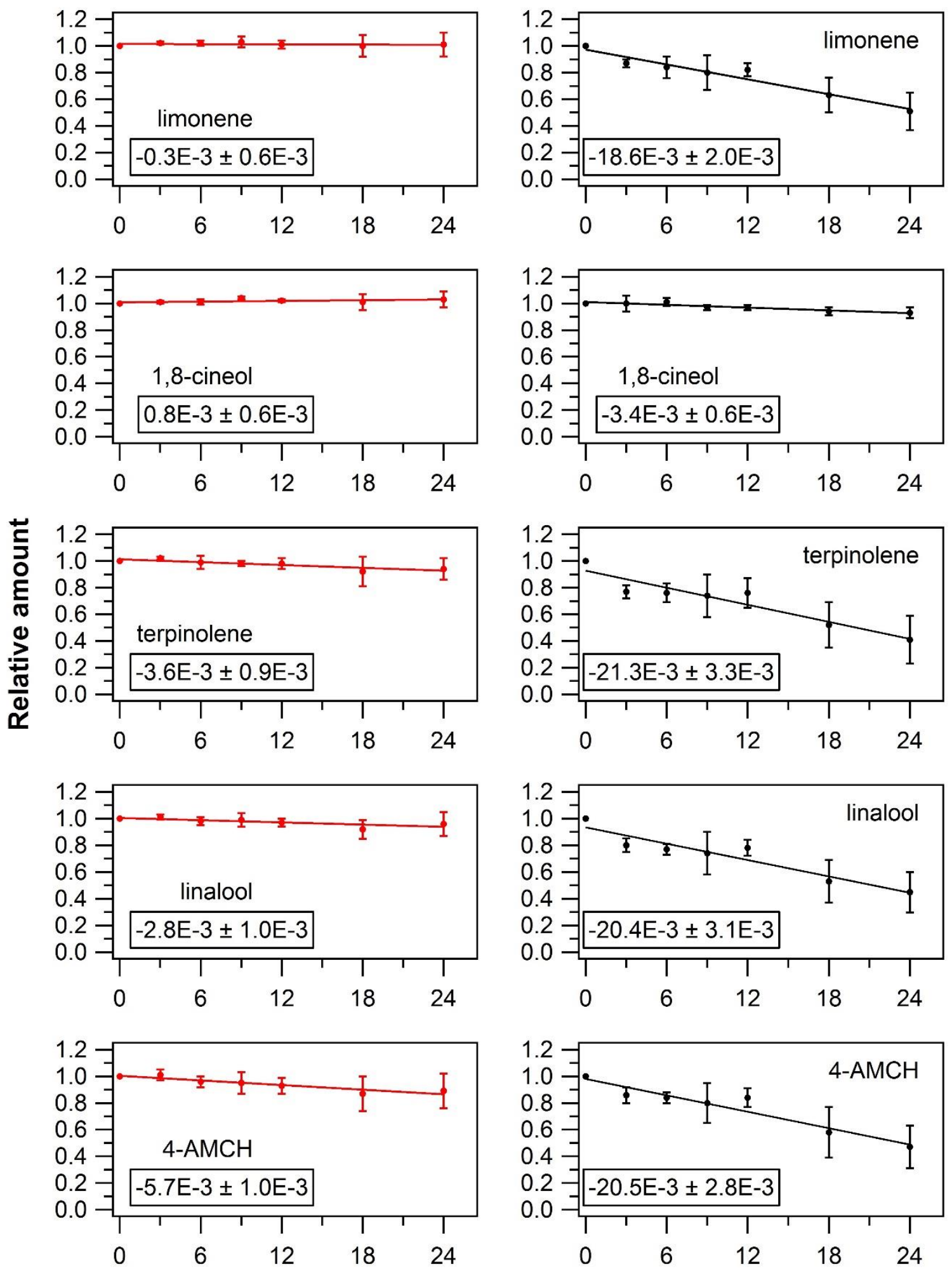

Purge volume (L)

Figure S17. (continued) 

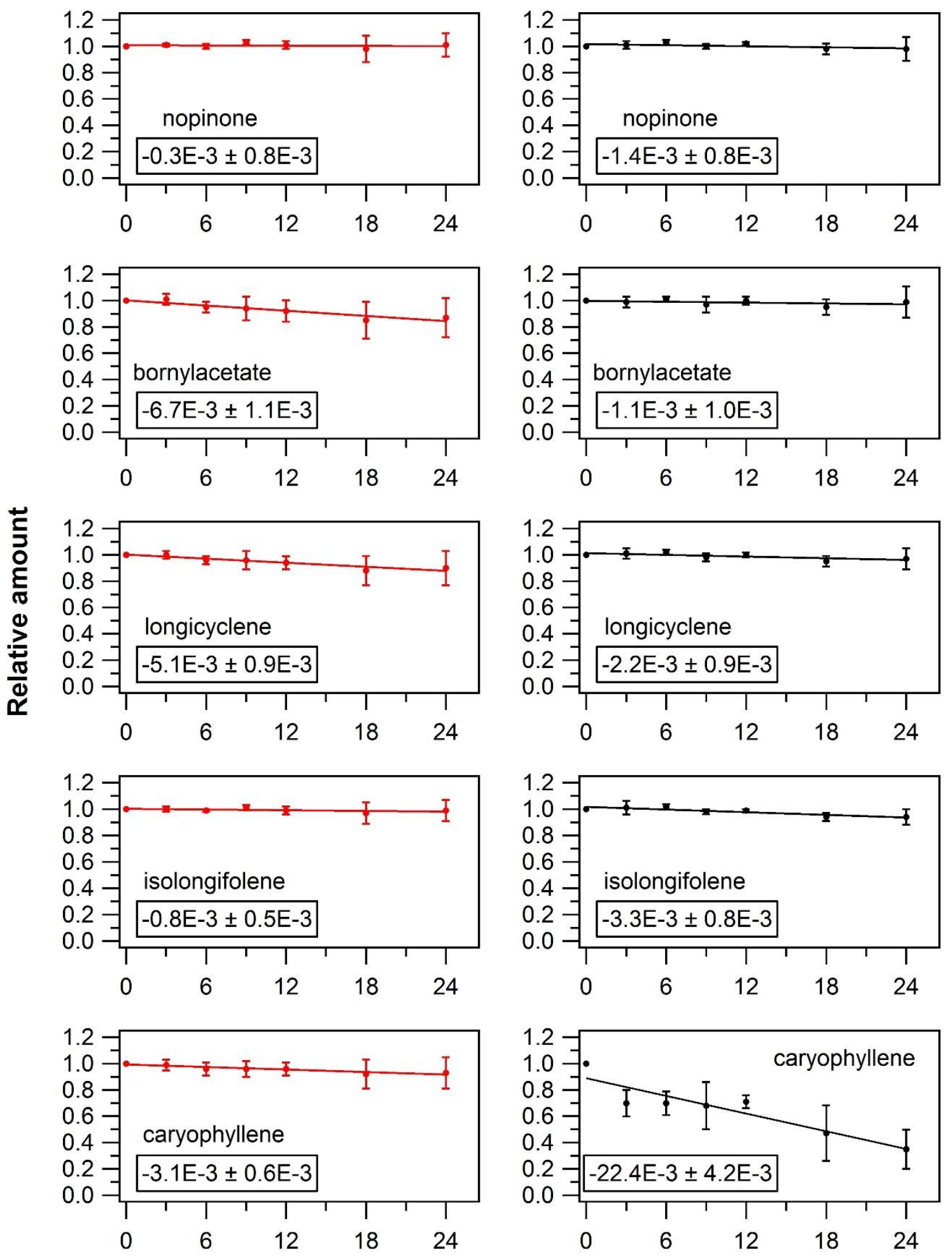

Purge volume (L)

Figure S17. (continued) 

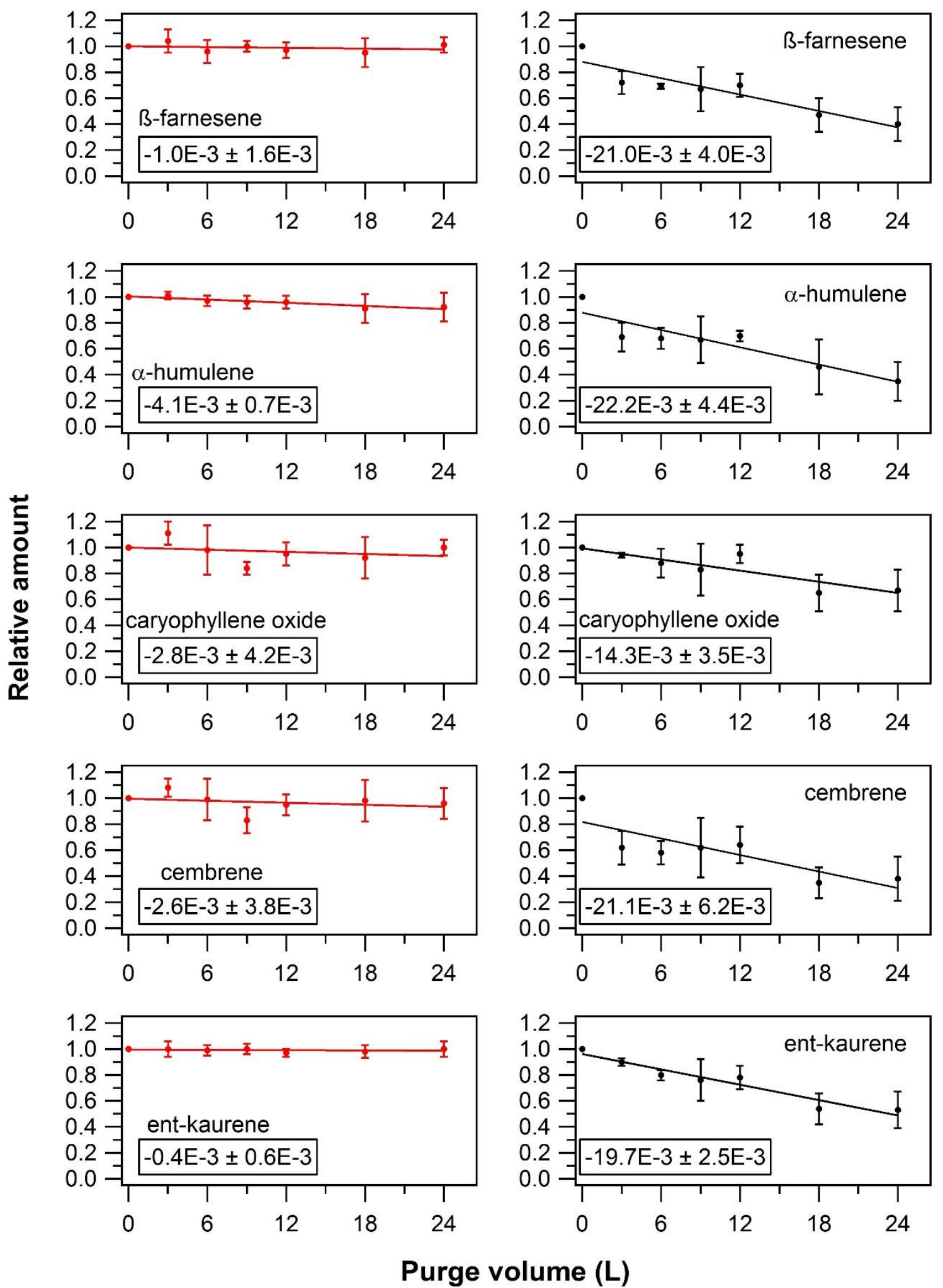

Figure S17. (continued) 

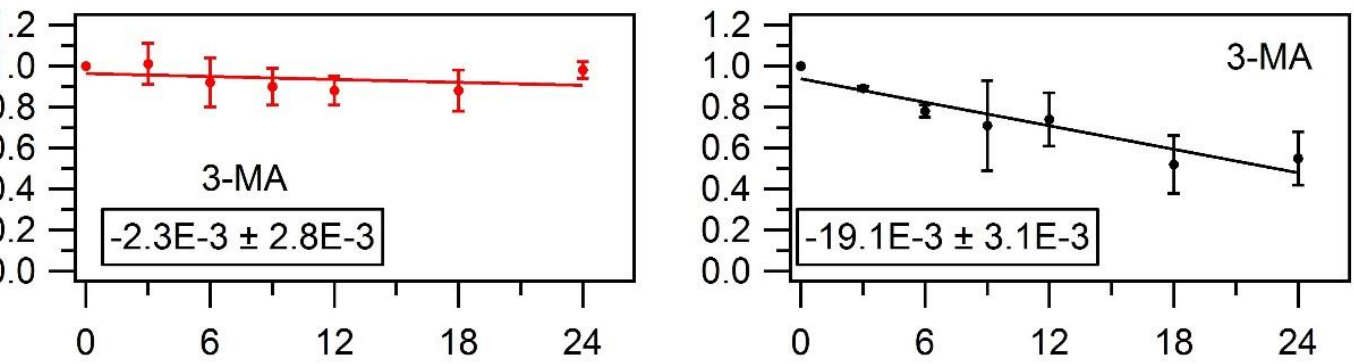

Figure S17. (continued)

Table S3. Literature retrieved $k_{\mathrm{O} 3}$ values and the estimated $k_{\mathrm{O} 3}$ values obtained based on main text Fig. 4 linear regression fit.

\begin{tabular}{|c|c|c|c|}
\hline Compound & $\begin{array}{c}k_{\mathrm{O} 3} \text { literature } \\
\left(\mathrm{cm}^{3} / \text { molecule }^{*} \mathrm{~s}\right)\end{array}$ & Reference & $\begin{array}{c}k_{\mathrm{O} 3} \text { estimated } \\
\left(\mathrm{cm}^{3} / \text { molecule }^{*} \mathrm{~s}\right)\end{array}$ \\
\hline$\alpha$-pinene & $9.6 * 10^{-17}$ & IUPAC ${ }^{a}$ & $(1.6 \pm 3.8) * 10^{-17}$ \\
\hline camphene & $5.0^{*} 10^{-19}$ & IUPAC & $(5.1 \pm 8.7)^{*} 10^{-18}$ \\
\hline$\beta$-pinene & $1.9 * 10^{-17}$ & IUPAC & $(7.7 \pm 14.8) * 10^{-18}$ \\
\hline 3-carene & $4.9 * 10^{-17}$ & IUPAC & $(5.2 \pm 15.7) * 10^{-17}$ \\
\hline$p$-cymene & - & - & $(3.4 \pm 5.4)^{*} 10^{-18}$ \\
\hline limonene & $2.2 * 10^{-16}$ & IUPAC & $(9.2 \pm 51.1) * 10^{-16}$ \\
\hline 1,8-cineol & - & - & $(6.6 \pm 12.1) * 10^{-18}$ \\
\hline terpinolene & $1.6^{*} 10^{-15}$ & IUPAC & $(2.6 \pm 17.5) * 10^{-15}$ \\
\hline linalool & - & - & $(1.8 \pm 11.1)^{*} 10^{-15}$ \\
\hline 4-AMCH & - & - & $(1.8 \pm 11.5) * 10^{-15}$ \\
\hline nopinone & - & - & $(3.4 \pm 5.3)^{*} 10^{-18}$ \\
\hline bornylacetate & - & - & $(2.9 \pm 4.4) * 10^{-18}$ \\
\hline longicyclene & - & - & $(4.4 \pm 7.3) * 10^{-18}$ \\
\hline isolongifolene & $1.0^{*} 10^{-17}$ & IUPAC & $(6.6 \pm 12.1)^{*} 10^{-18}$ \\
\hline$\beta$-caryophyllene & $1.2 * 10^{-14}$ & IUPAC & $(3.4 \pm 23.9) * 10^{-15}$ \\
\hline$\beta$-farnesene & $5.6^{*} 10^{-16}$ & IUPAC & $(2.1 \pm 13.3) * 10^{-15}$ \\
\hline$\alpha$-humulene & $1.2 * 10^{-14}$ & IUPAC & $(3.1 \pm 21.7) * 10^{-15}$ \\
\hline caryophyllene oxide & $1.2 * 10^{-17}$ & EPISuite $^{\mathrm{b}}$ & $(2.6 \pm 10.9) * 10^{-16}$ \\
\hline cembrene & $1.9 * 10^{-15}$ & EPISuite & $(2.3 \pm 15.5) * 10^{-15}$ \\
\hline ent-kaurene & $1.2 * 10^{-17}$ & EPISuite & $(1.4 \pm 8.2)^{*} 10^{-15}$ \\
\hline 3-MA & - & - & $(1.1 \pm 6.5) * 10^{-15}$ \\
\hline
\end{tabular}

${ }^{a}$ IUPAC Task Group on Atmospheric Chemical Kinetic Data Evaluation (http://iupac.pole-ether.fr)

${ }^{\mathrm{b}}$ EPISuite, Environmental Protection Agency, United States (https://www.epa.gov/tsca-screening-tools) 
Table S4. Tentative identification of diterpenes (DTs) and alike high-molecular weight compounds (categorised here as biogenic volatile organic compounds, BVOCs) in dynamic headspace samples of pine needles and spruce twigs.

\begin{tabular}{|c|c|c|c|c|c|}
\hline Sample & $\begin{array}{c}\text { Peak } \\
\text { no. }^{\text {a }}\end{array}$ & $\mathbf{R} \mathbf{I}^{\mathrm{b}}$ & Formula $^{\mathrm{c}}$ & CAS & Name or $\mathbf{m} / \mathbf{z}$ peaks ${ }^{d}$ \\
\hline \multirow[t]{13}{*}{ pine } & 1 & 1914 (1914) & $\mathrm{C}_{19} \mathrm{H}_{30}(\mathrm{BVOC})$ & - & $\underline{243}, 123,133,258$ \\
\hline & 2 & 1944 (1943) & $\mathrm{C}_{19} \mathrm{H}_{28}(\mathrm{BVOC})$ & - & $\underline{91}, 79,241,256$ \\
\hline & 3 & 1957 (1957) & $\mathrm{C}_{18} \mathrm{H}_{26} \mathrm{O}(\mathrm{BVOC})$ & - & $\underline{123}, 81,243,258$ \\
\hline & 4 & 1966 (1966) & $\mathrm{C}_{19-20} \mathrm{H}_{32} \mathrm{O}_{0-2}(\mathrm{BVOC})$ & - & $\underline{81}, 178,243,261$ \\
\hline & 5 & 1977 (1976) & $\mathrm{C}_{20} \mathrm{H}_{32}(\mathrm{DT})$ & - & $\underline{257}, 243,272,79$ \\
\hline & 6 & 1997 (1997) & $\mathrm{C}_{20} \mathrm{H}_{32}(\mathrm{DT})$ & $1686-56-2$ & sandaracopimaradiene \\
\hline & 7 & 2016 (2016) & $\mathrm{C}_{19-20} \mathrm{H}_{28} \mathrm{O}_{0-1}(\mathrm{BVOC})$ & - & $\underline{159}, 241,185,256$ \\
\hline & 8 & $2025(2025)$ & $\mathrm{C}_{20} \mathrm{H}_{30-32} \mathrm{O}_{0-2}(\mathrm{BVOC})$ & - & $\underline{91}, 134,92,123$ \\
\hline & 9 & $2043(2042)$ & $\mathrm{C}_{20} \mathrm{H}_{34} \mathrm{O}(\mathrm{DT})$ & $1227-93-6$ & 13-epi-manool oxide \\
\hline & 10 & $2051(2050)$ & $\mathrm{C}_{19-20} \mathrm{H}_{28-32} \mathrm{O}_{0-1}(\mathrm{BVOC})$ & - & $\underline{79}, 91,105272$ \\
\hline & 11 & 2058 (2058) & $\mathrm{C}_{19-20} \mathrm{H}_{28} \mathrm{O}_{0-1}(\mathrm{BVOC})$ & - & $\underline{159}, 241,185,256$ \\
\hline & 12 & 2065 (2064) & $\mathrm{C}_{20} \mathrm{H}_{34} \mathrm{O}(\mathrm{DT})$ & - & $\underline{257}, 275,81,69$ \\
\hline & 13 & $2136(2136)$ & $\mathrm{C}_{20} \mathrm{H}_{32}(\mathrm{DT})$ & $35241-40-8$ & abietadiene \\
\hline \multirow[t]{14}{*}{ spruce } & 1 & 1914 (1914) & $\mathrm{C}_{20} \mathrm{H}_{32}(\mathrm{DT})$ & $1686-67-5$ & rimuene \\
\hline & 2 & $1940(1940)$ & $\mathrm{C}_{20} \mathrm{H}_{32}(\mathrm{DT})$ & - & $\underline{257}, 272,67,81$ \\
\hline & 3 & 1958 (1958) & $\mathrm{C}_{20} \mathrm{H}_{32}(\mathrm{DT})$ & $1898-13-1$ & cembrene \\
\hline & 4 & 1990 (1989) & $\mathrm{C}_{20} \mathrm{H}_{32}(\mathrm{DT})$ & $71213-92-8$ & cembrene A \\
\hline & 5 & 2014 (2014) & $\mathrm{C}_{20} \mathrm{H}_{32}(\mathrm{DT})$ & - & $\underline{137}, 136,91,257$ \\
\hline & 6 & $2025(2025)$ & $\mathrm{C}_{20} \mathrm{H}_{32}(\mathrm{DT})$ & - & $\underline{120}, 106,133,272$ \\
\hline & 7 & $2033(2032)$ & $\mathrm{C}_{20} \mathrm{H}_{32}(\mathrm{DT})$ & - & $\underline{136}, 121,93,272$ \\
\hline & 8 & $2040(2040)$ & $\mathrm{C}_{20} \mathrm{H}_{34} \mathrm{O}(\mathrm{DT})$ & $1227-93-6$ & 13-epi-manool oxide \\
\hline & 9 & 2048 (2047) & $\mathrm{C}_{20} \mathrm{H}_{32}(\mathrm{DT})$ & - & $\underline{119}, 93,257,272$ \\
\hline & 10 & 2054 (2053) & $\mathrm{C}_{19-20} \mathrm{H}_{28-30}(\mathrm{BVOC})$ & - & $\underline{159}, \underline{257}, 241,272$ \\
\hline & 11 & $2062(2062)$ & $\mathrm{C}_{20} \mathrm{H}_{34} \mathrm{O}(\mathrm{DT})$ & - & $\underline{257}, 275,123,147$ \\
\hline & 12 & $2081(2081)$ & $\mathrm{C}_{20} \mathrm{H}_{32}(\mathrm{DT})$ & - & $\underline{81}, 229,257,272$ \\
\hline & 13 & 2094 (2094) & $\mathrm{C}_{20} \mathrm{H}_{30}(\mathrm{DT})$ & $19407-28-4$ & abietatriene \\
\hline & 14 & $2133(2133)$ & $\mathrm{C}_{20} \mathrm{H}_{32}(\mathrm{DT})$ & - & $\underline{272}, 55,96,131$ \\
\hline
\end{tabular}

${ }^{\text {a }}$ Peak number marked in the manuscript Figs. 6 and 7.

${ }^{\mathrm{b}}$ Retention index (RI) values presented as Kovats index (and arithmetic index in brackets).

${ }^{\mathrm{c}}$ Proposed or tentatively identified formula of the compound.

${ }^{\mathrm{d}}$ The presented $\mathrm{m} / \mathrm{z}$ ions are either the most abundant ions or $\mathrm{m} / \mathrm{z}$ ions considered to be characteristic for the specific peak. The underlined $\mathrm{m} / \mathrm{z}$ ion is the most abundant one. 

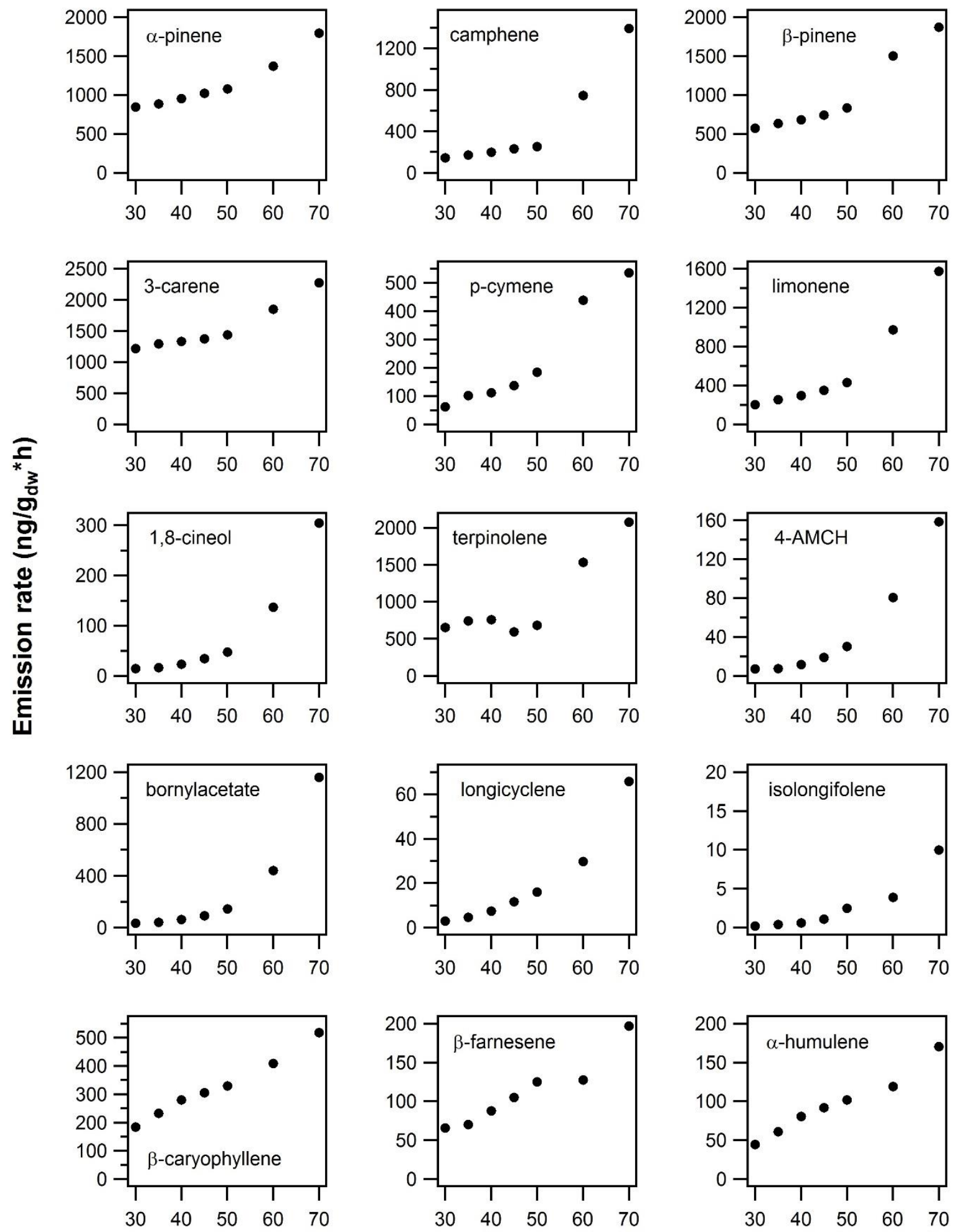

\section{Temperature $\left({ }^{\circ} \mathrm{C}\right)$}

Figure S18. Terpenoid emission rates from pine needles as a function of oven temperature in the dynamic headspace extraction experiments. 

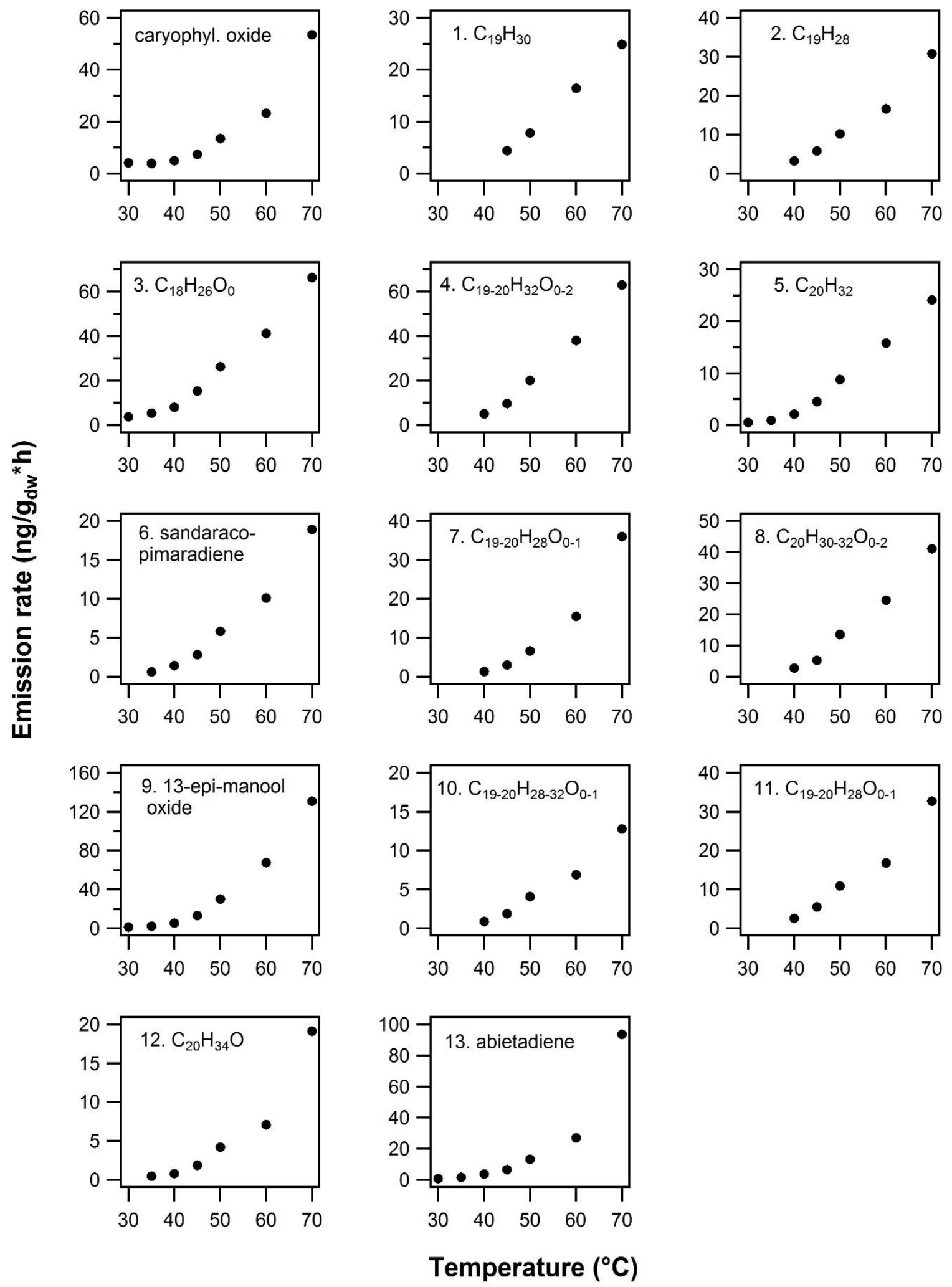

Figure S18. (continued) 

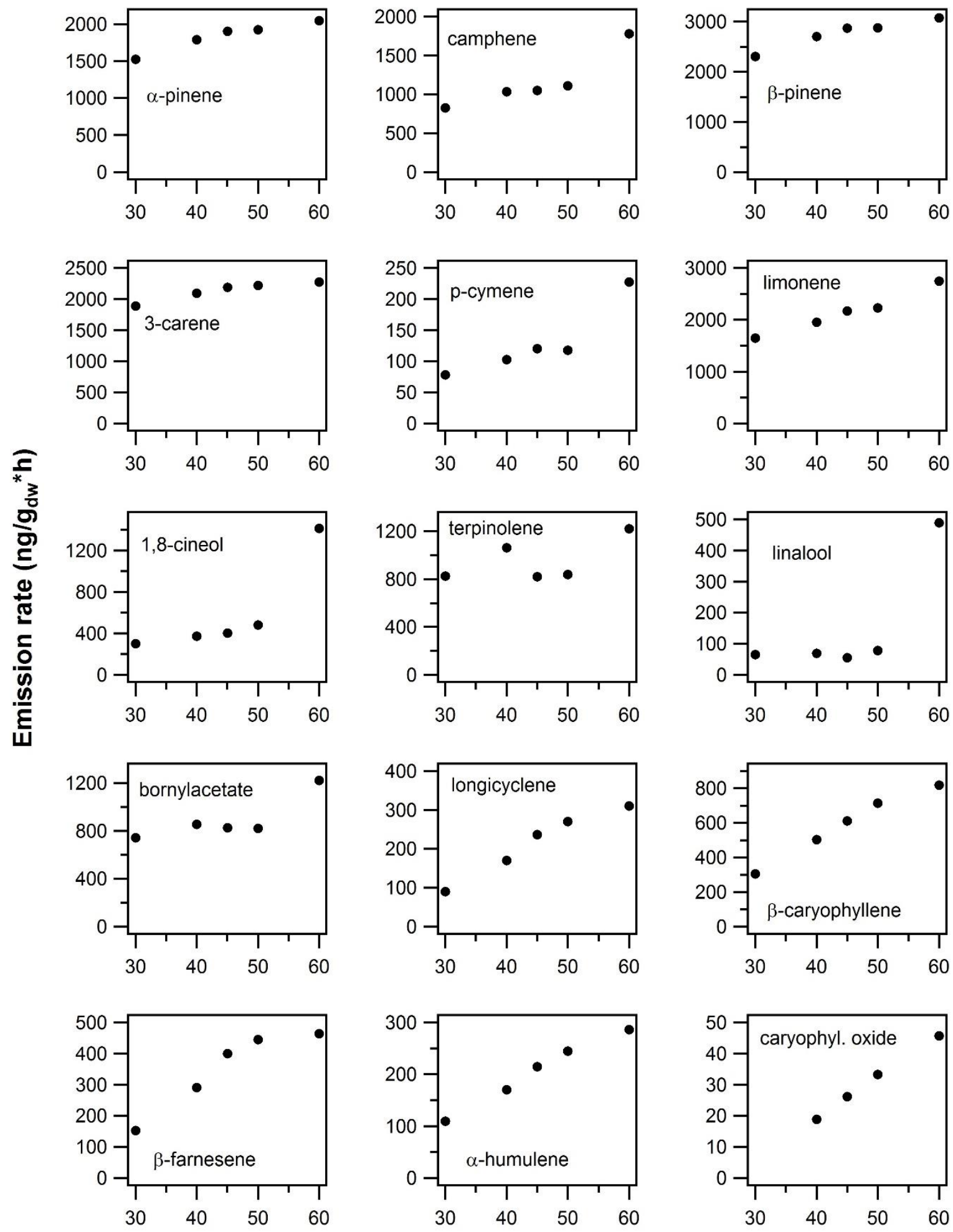

Temperature $\left({ }^{\circ} \mathrm{C}\right)$

Figure S19. Terpenoid emission rates from spruce twigs as a function of oven temperature in the dynamic headspace extraction experiments. 

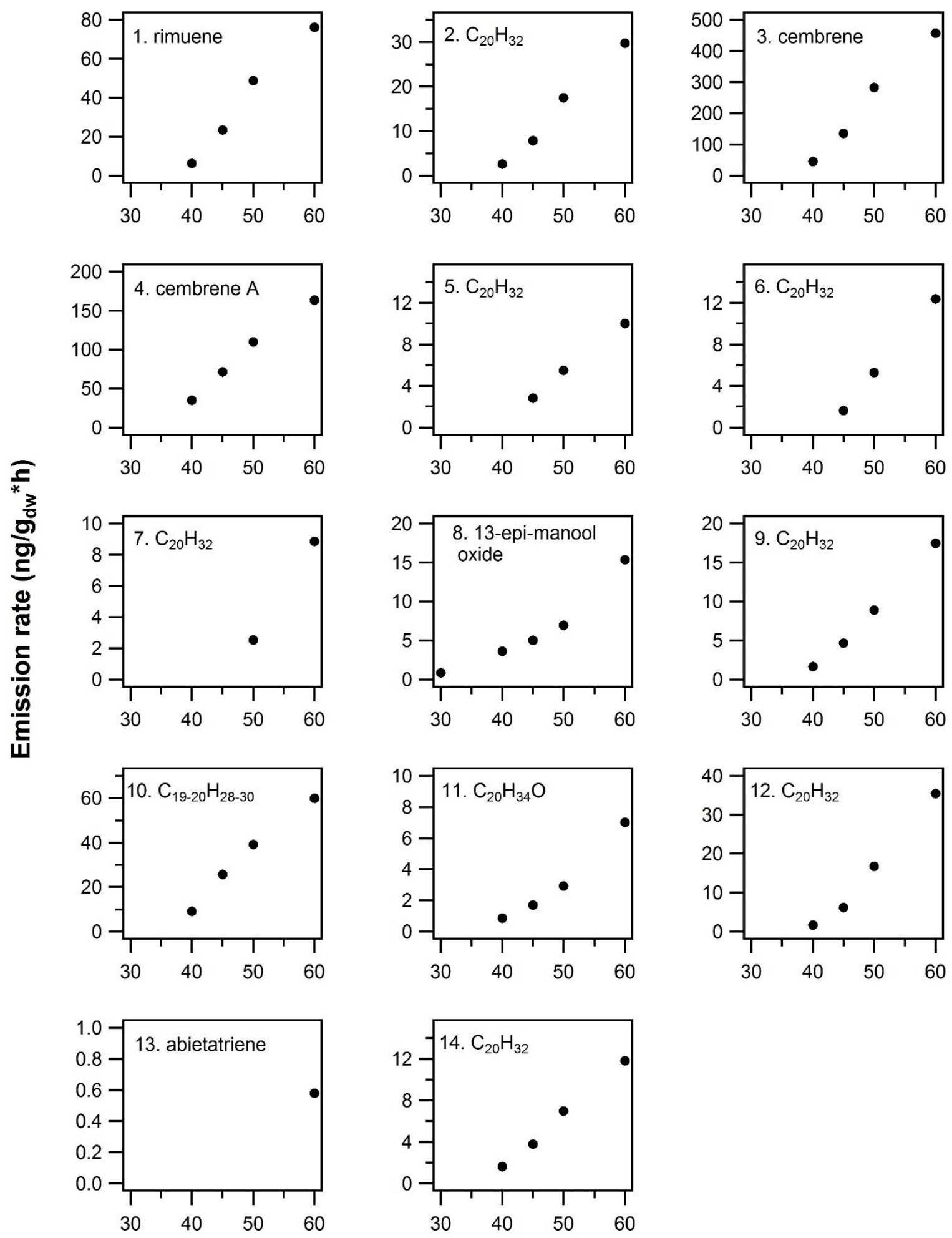

Temperature $\left({ }^{\circ} \mathrm{C}\right)$

Figure S19. (continued) 
Table S5. Results from the spruce branch enclosure experiments.

\begin{tabular}{|c|c|c|c|c|c|c|}
\hline $\mathrm{KI}^{\mathrm{a}}$ & $\mathrm{AI}^{\mathrm{b}}$ & Formula $^{\mathrm{c}}$ & CAS & Name or $\mathrm{m} / \mathrm{z}$ peaks ${ }^{\mathrm{d}}$ & $\begin{array}{c}\text { Emission rate } \\
\left(\mathrm{ng} / \mathrm{g}_{\mathrm{dw}} * \mathrm{~h}\right)\end{array}$ & $\begin{array}{c}\text { Emission rate }^{\mathrm{f}} \\
\left(\mathrm{ng} / \mathrm{g}_{\mathrm{dw}} * \mathrm{~h}\right)\end{array}$ \\
\hline $943 \pm 1$ & $940 \pm 1$ & $\mathrm{C}_{10} \mathrm{H}_{16}(\mathrm{MT})$ & $7785-70-8$ & $\alpha$-pinene & $3630 \pm 239$ & $5674 \pm 373$ \\
\hline $961 \pm 1$ & $958 \pm 1$ & $\mathrm{C}_{10} \mathrm{H}_{16}(\mathrm{MT})$ & $79-92-5$ & camphene & $1797 \pm 118$ & $5048 \pm 332$ \\
\hline $981 \pm 1$ & $979 \pm 1$ & $\mathrm{C}_{10} \mathrm{H}_{16}(\mathrm{MT})$ & $3387-41-5$ & sabinene & $589 \pm 39$ & $1449 \pm 95$ \\
\hline $988 \pm 1$ & $986 \pm 1$ & $\mathrm{C}_{10} \mathrm{H}_{16}(\mathrm{MT})$ & 19902-08-0 & $\beta$-pinene & $3975 \pm 261$ & $6045 \pm 398$ \\
\hline $992 \pm 0$ & $991 \pm 0$ & $\mathrm{C}_{10} \mathrm{H}_{16}(\mathrm{MT})$ & $123-35-3$ & myrcene & $1999 \pm 131$ & $3690 \pm 243$ \\
\hline $1014 \pm 1$ & $1013 \pm 1$ & $\mathrm{C}_{10} \mathrm{H}_{16}(\mathrm{MT})$ & $99-83-2$ & $\alpha$-phellandrene & $246 \pm 16$ & $1482 \pm 97$ \\
\hline $1018 \pm 1$ & $1016 \pm 1$ & $\mathrm{C}_{10} \mathrm{H}_{16}(\mathrm{MT})$ & $498-15-7$ & 3-carene & $655 \pm 43$ & $1304 \pm 86$ \\
\hline $1033 \pm 1$ & $1030 \pm 1$ & $\mathrm{C}_{10} \mathrm{H}_{14}(\mathrm{MT})$ & $99-87-6$ & $p$-cymene & $385 \pm 25$ & $982 \pm 65$ \\
\hline $1039 \pm 1$ & $1036 \pm 1$ & $\mathrm{C}_{10} \mathrm{H}_{16}(\mathrm{MT})$ & $5989-54-8$ & limonene & $8722 \pm 574$ & $19443 \pm 1279$ \\
\hline $1043 \pm 1$ & $1040 \pm 1$ & $\mathrm{C}_{10} \mathrm{H}_{18} \mathrm{O}(\mathrm{MT})$ & $470-82-6$ & 1,8-cineol & $9001 \pm 592$ & $13276 \pm 873$ \\
\hline $1051 \pm 1$ & $1048 \pm 1$ & $\mathrm{C}_{10} \mathrm{H}_{16}(\mathrm{MT})$ & $3338-55-4$ & $\beta$-ocimene & $1523 \pm 100$ & $3648 \pm 240$ \\
\hline $1067 \pm 0$ & $1064 \pm 0$ & $\mathrm{C}_{10} \mathrm{H}_{16}(\mathrm{MT})$ & $99-85-4$ & $\gamma$-terpinene & $2881 \pm 189$ & $7296 \pm 480$ \\
\hline $1079 \pm 0$ & $1077 \pm 0$ & $\mathrm{C}_{10} \mathrm{H}_{18} \mathrm{O}(\mathrm{MT})$ & - & $\underline{93}, 71,121,136$ & $193 \pm 13$ & $1201 \pm 79$ \\
\hline $1093 \pm 1$ & $1092 \pm 1$ & $\mathrm{C}_{10} \mathrm{H}_{16}(\mathrm{MT})$ & $586-62-9$ & terpinolene & $592 \pm 39$ & $1452 \pm 95$ \\
\hline $1102 \pm 1$ & $1102 \pm 1$ & $\mathrm{C}_{10} \mathrm{H}_{18} \mathrm{O}(\mathrm{MT})$ & $78-70-6$ & linalool & $2733 \pm 180$ & $5266 \pm 346$ \\
\hline $1162 \pm 1$ & $1160 \pm 1$ & $\mathrm{C}_{10} \mathrm{H}_{16} \mathrm{O}(\mathrm{MT})$ & $76-22-2$ & camphor & $14848 \pm 977$ & $23930 \pm 1574$ \\
\hline $1170 \pm 1$ & $1169 \pm 1$ & $\mathrm{C}_{10} \mathrm{H}_{18} \mathrm{O}(\mathrm{MT})$ & - & $\underline{71}, 136,139,154$ & $4409 \pm 290$ & $6486 \pm 427$ \\
\hline $1185 \pm 0$ & $1184 \pm 0$ & $\mathrm{C}_{10} \mathrm{H}_{18} \mathrm{O}(\mathrm{MT})$ & $507-70-0$ & borneol & $24667 \pm 1623$ & $43849 \pm 2884$ \\
\hline $1191 \pm 0$ & $1190 \pm 0$ & $\mathrm{C}_{10} \mathrm{H}_{18} \mathrm{O}(\mathrm{MT})$ & $562-74-3$ & terpinen-4-ol & $4867 \pm 320$ & $6779 \pm 446$ \\
\hline $1205 \pm 0$ & $1204 \pm 0$ & $\mathrm{C}_{10} \mathrm{H}_{18} \mathrm{O}(\mathrm{MT})$ & $98-55-5$ & $\alpha$-terpineol & $13494 \pm 888$ & $18170 \pm 1195$ \\
\hline $1220 \pm 0$ & $1219 \pm 0$ & $\mathrm{C}_{10} \mathrm{H}_{14} \mathrm{O}(\mathrm{MT})$ & $80-57-9$ & verbenone & $2451 \pm 161$ & $4439 \pm 292$ \\
\hline $1229 \pm 1$ & $1228 \pm 1$ & $\mathrm{C}_{10} \mathrm{H}_{20} \mathrm{O}(\mathrm{MT})$ & $106-22-9$ & citronellol & $4726 \pm 311$ & $8600 \pm 566$ \\
\hline $1266 \pm 1$ & $1265 \pm 1$ & $\mathrm{C}_{10} \mathrm{H}_{16} \mathrm{O}(\mathrm{MT})$ & $89-81-6$ & piperitone & $6317 \pm 416$ & $9919 \pm 652$ \\
\hline $1294 \pm 1$ & $1293 \pm 1$ & $\mathrm{C}_{12} \mathrm{H}_{20} \mathrm{O}_{2}$ (BVOC) & $5655-61-8$ & bornylacetate & $2976 \pm 196$ & $6721 \pm 442$ \\
\hline $1348 \pm 1$ & $1346 \pm 1$ & $\mathrm{C}_{12} \mathrm{H}_{20} \mathrm{O}_{3}$ (BVOC) & - & $\underline{108}, \underline{71}, 126,212$ & $128 \pm 8$ & $1676 \pm 110$ \\
\hline $1355 \pm 0$ & $1354 \pm 0$ & $\mathrm{C}_{12} \mathrm{H}_{20} \mathrm{O}_{2}$ (BVOC) & $80-26-2$ & $\alpha$-terpinyl acetate & $1789 \pm 118$ & $3812 \pm 251$ \\
\hline $1360 \pm 1$ & $1359 \pm 1$ & $\mathrm{C}_{10} \mathrm{H}_{12} \mathrm{O}_{2}(\mathrm{MT})$ & $97-53-0$ & eugenol & $121 \pm 8$ & $542 \pm 36$ \\
\hline $1370 \pm 1$ & $1369 \pm 1$ & $\mathrm{C}_{15} \mathrm{H}_{24}(\mathrm{SQT})$ & $5989-08-2$ & $\alpha$-longipinene & $325 \pm 21$ & $744 \pm 49$ \\
\hline $1378 \pm 1$ & $1377 \pm 1$ & $\mathrm{C}_{11-12} \mathrm{H}_{18-20} \mathrm{O}_{2}(\mathrm{BVOC})$ & - & $\underline{69}, 67,93,121$ & $244 \pm 16$ & $1375 \pm 90$ \\
\hline $1401 \pm 0$ & $1401 \pm 0$ & $\mathrm{C}_{11} \mathrm{H}_{14} \mathrm{O}_{2}(\mathrm{BVOC})$ & - & $\underline{178}, 147,163,107$ & $40 \pm 3$ & $327 \pm 22$ \\
\hline $1423 \pm 0$ & $1423 \pm 0$ & $\mathrm{C}_{10} \mathrm{H}_{16} \mathrm{O}(\mathrm{MT})$ & - & $\underline{109}, 67,137,152$ & - & $624 \pm 41$ \\
\hline $1435 \pm 0$ & $1434 \pm 0$ & $\mathrm{C}_{15} \mathrm{H}_{24}(\mathrm{SQT})$ & - & $\underline{161}, 105,159,204$ & $230 \pm 15$ & $668 \pm 44$ \\
\hline $1441 \pm 1$ & $1440 \pm 1$ & $\mathrm{C}_{15} \mathrm{H}_{24}(\mathrm{SQT})$ & $87-44-5$ & $\beta$-caryophyllene & $100 \pm 7$ & $686 \pm 45$ \\
\hline $1458 \pm 1$ & $1457 \pm 1$ & $\mathrm{C}_{15} \mathrm{H}_{24}(\mathrm{SQT})$ & $18794-84-8$ & $\beta$-farnesene & $740 \pm 49$ & $1122 \pm 74$ \\
\hline $1477 \pm 1$ & $1477 \pm 1$ & $\mathrm{C}_{15} \mathrm{H}_{24}(\mathrm{SQT})$ & $6753-98-6$ & $\alpha$-humulene & $102 \pm 7$ & $179 \pm 12$ \\
\hline $1501 \pm 1$ & $1501 \pm 1$ & $\mathrm{C}_{15} \mathrm{H}_{24}(\mathrm{SQT})$ & $23986-74-5$ & germacrene D & $330 \pm 22$ & $694 \pm 46$ \\
\hline $1508 \pm 0$ & $1508 \pm 0$ & $\mathrm{C}_{15} \mathrm{H}_{24}(\mathrm{SQT})$ & - & $\underline{69}, 93,55,119$ & $118 \pm 8$ & $414 \pm 27$ \\
\hline $1514 \pm 1$ & $1513 \pm 1$ & $\mathrm{C}_{15} \mathrm{H}_{24}(\mathrm{SQT})$ & - & $\underline{161}, \underline{105}, 91,204$ & $100 \pm 7$ & $459 \pm 30$ \\
\hline $1552 \pm 2$ & $1551 \pm 2$ & $\mathrm{C}_{15} \mathrm{H}_{24}(\mathrm{SQT})$ & - & $\underline{93}, 121,136,204$ & $732 \pm 48$ & $987 \pm 65$ \\
\hline
\end{tabular}


Table S5. (continued)

\begin{tabular}{|c|c|c|c|c|c|c|}
\hline $\mathrm{KI}^{\mathrm{a}}$ & $\mathrm{AI}^{\mathrm{b}}$ & Formula $^{c}$ & CAS & Name or $\mathrm{m} / \mathrm{z}$ peaks ${ }^{\mathrm{d}}$ & $\begin{array}{c}\text { Emission rate } \\
\left(\mathrm{ng} / \mathrm{g}_{\mathrm{dw}} * \mathrm{~h}\right)\end{array}$ & $\begin{array}{c}\text { Emission rate } \\
\left(\mathrm{ng} / \mathrm{g}_{\mathrm{dw}} * \mathrm{~h}\right)\end{array}$ \\
\hline $1597 \pm 1$ & $1597 \pm 1$ & $\mathrm{C}_{15} \mathrm{H}_{24} \mathrm{O}_{0-1}(\mathrm{SQT})$ & - & $\underline{159}, \underline{161}, 105,79$ & $429 \pm 28$ & $891 \pm 59$ \\
\hline $1607 \pm 1$ & $1606 \pm 1$ & $\mathrm{C}_{15} \mathrm{H}_{24} \mathrm{O}(\mathrm{SQT})$ & $1139-30-6$ & caryophyllene oxide & - & $423 \pm 28$ \\
\hline $1731 \pm 0$ & $1730 \pm 0$ & $\mathrm{C}_{15} \mathrm{H}_{24} \mathrm{O}$ (SQT) & - & $\underline{177}, 159,131,220$ & - & $356 \pm 23$ \\
\hline $1757 \pm 1$ & $1756 \pm 1$ & $\mathrm{C}_{15} \mathrm{H}_{26} \mathrm{O}_{2}$ (BVOC) & - & $\underline{153}, 135,177,238$ & $377 \pm 25$ & $1523 \pm 100$ \\
\hline $1786 \pm 2$ & $1786 \pm 2$ & $\mathrm{C}_{14} \mathrm{H}_{12} \mathrm{O}_{2}$ (BVOC) & $120-51-4$ & benzyl benzoate & $605 \pm 40$ & $1075 \pm 71$ \\
\hline $1840 \pm 0$ & $1840 \pm 0$ & $\mathrm{C}_{15} \mathrm{H}_{24} \mathrm{O}(\mathrm{SQT})$ & - & $\underline{162}, 55,159,220$ & - & $239 \pm 16$ \\
\hline $1851 \pm 0$ & $1850 \pm 0$ & $\mathrm{C}_{15} \mathrm{H}_{24} \mathrm{O}(\mathrm{SQT})$ & - & $\underline{159}, 187,220,202$ & - & $1108 \pm 73$ \\
\hline $1892 \pm 2$ & $1892 \pm 2$ & $\mathrm{C}_{14} \mathrm{H}_{12} \mathrm{O}_{3}$ (BVOC) & $118-58-1$ & benzyl salicylate & $1010 \pm 66$ & $1273 \pm 84$ \\
\hline $1909 \pm 1$ & $1905 \pm 6$ & $\mathrm{C}_{20} \mathrm{H}_{32}(\mathrm{DT})$ & $1686-67-5$ & rimuene & $38 \pm 3$ & $462 \pm 30$ \\
\hline $1953 \pm 1$ & $1952 \pm 1$ & $\mathrm{C}_{20} \mathrm{H}_{32}(\mathrm{DT})$ & 1898-13-1 & cembrene & $15 \pm 1$ & $158 \pm 10$ \\
\hline $1959 \pm 0$ & $1959 \pm 0$ & $\mathrm{C}_{16} \mathrm{H}_{30} \mathrm{O}_{2}$ (BVOC) & - & $\underline{55}, 69,236,254$ & $14 \pm 1$ & $244 \pm 16$ \\
\hline $1979 \pm 1$ & $1979 \pm 1$ & $\begin{array}{c}\mathrm{C}_{20-22} \mathrm{H}_{32-36} \mathrm{O}_{0-2} \\
\text { (BVOC) }\end{array}$ & - & $\underline{55}, 106,257,272$ & $5 \pm 0$ & $69 \pm 5$ \\
\hline $2015 \pm 1$ & $2015 \pm 1$ & $\mathrm{C}_{20} \mathrm{H}_{32}(\mathrm{DT})$ & - & $\underline{120}, 106,133,272$ & $11 \pm 1$ & $318 \pm 21$ \\
\hline $2070 \pm 0$ & $2069 \pm 0$ & $\mathrm{C}_{20} \mathrm{H}_{32}(\mathrm{DT})$ & - & $\underline{55}, 229,257,272$ & $25 \pm 2$ & $364 \pm 24$ \\
\hline $2084 \pm 1$ & $2084 \pm 1$ & $\mathrm{C}_{20} \mathrm{H}_{34} \mathrm{O}(\mathrm{DT})$ & $1438-62-6$ & 13-epi-manool & $238 \pm 16$ & $750 \pm 49$ \\
\hline $2266 \pm 1$ & $2266 \pm 1$ & $\mathrm{C}_{20} \mathrm{H}_{32}(\mathrm{DT})$ & - & $\underline{55}, 133,120,272$ & $75 \pm 5$ & $462 \pm 30$ \\
\hline
\end{tabular}

${ }^{\text {a }}$ Kovats index (KI), TD-GC-MS2 was used for analysis.

${ }^{\mathrm{b}}$ Arithmetic index (AI), TD-GC-MS2 was used for analysis.

${ }^{\mathrm{c}}$ Identified or proposed compound formula.

${ }^{d}$ the $\mathrm{m} / \mathrm{z}$ peaks correspond to either the most abundant peaks or to peaks considered to be characteristic for the specific unknown compound.

${ }^{\mathrm{e}}$ Emission rate results obtained at $60 \pm 1{ }^{\circ} \mathrm{C}$ on the $6^{\text {th }}$ of August, 2019.

${ }^{\mathrm{f}}$ Emission rate results obtained at $59 \pm 1{ }^{\circ} \mathrm{C}$ on the $10^{\text {th }}$ of August, 2019. 


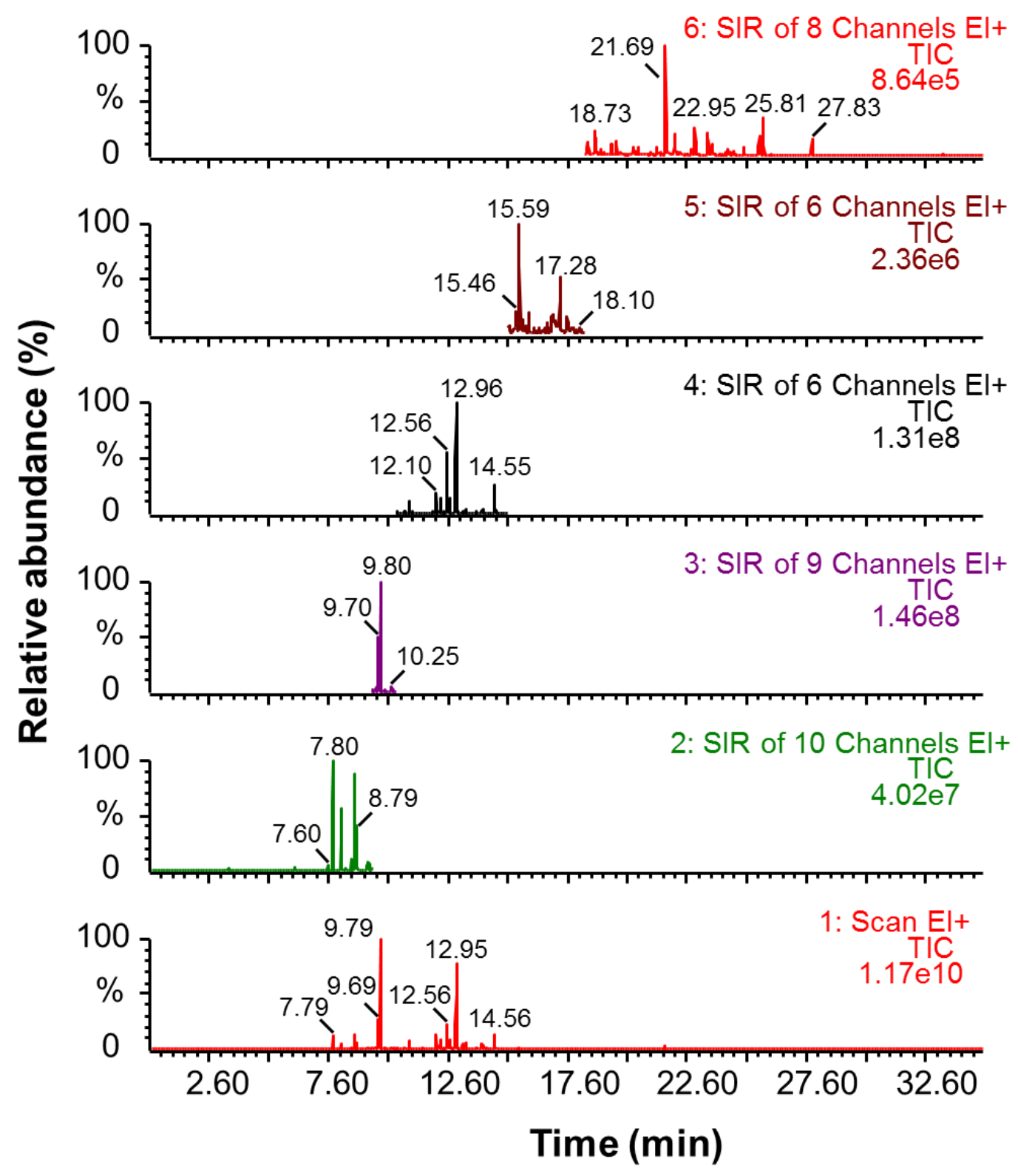

Figure S20. Example of total ion chromatogram (bottom) and selected ion recording (SIR, 2-6) chromatograms from the TD-GC-MS2 analysis of spruce branch enclosure experiment sample on the $10^{\text {th }}$ of August, 2019 (sampling at $59 \pm 1{ }^{\circ} \mathrm{C}$ for $30 \mathrm{~min}$ at flow rate of $100 \mathrm{~mL} / \mathrm{min}$ ). 